\title{
Quantitative Aspects of and Ionization Mechanisms in Positive-Ion Atmospheric Pressure Chemical Ionization Mass Spectrometry
}

\author{
Lisandra Cubero Herrera,* J. Stuart Grossert, and Louis Ramaley \\ Department of Chemistry, Dalhousie University, Halifax, Nova Scotia, Canada
}

The behavior in atmospheric pressure chemical ionization of selected model polycyclic aromatic compounds, pyrene, dibenzothiophene, carbazole, and fluorenone, was studied in the solvents acetonitrile, methanol, and toluene. Relative ionization efficiency and sensitivity were highest in toluene and lowest in methanol, a mixture of molecular ions and protonated molecules was observed in most instances, and interferences between analytes were detected at higher concentrations. Such interferences were assumed to be caused by a competition among analyte molecules for a limited number of reagent ions in the plasma. The presence of both molecular ions and protonated analyte molecules can be attributed to charge-transfer from solvent radical cations and proton transfer from protonated solvent molecules, respectively. The order of ionization efficiency could be explained by incorporating the effect of solvation in the ionization reactions. Thermodynamic data, both experimental and calculated theoretically, are presented to support the proposed ionization mechanisms. The analytical implications of the results are that using acetonitrile (compared with methanol) as solvent will provide better sensitivity with fewer interferences (at low concentrations), except for analytes having high gas-phase basicities. (J Am Soc Mass Spectrom 2008, 19, 1926-1941) (c) 2008 Published by Elsevier Inc. on behalf of American Society for Mass Spectrometry

$\mathrm{T}$ The analysis of polycyclic aromatic compounds (PACs) in petroleum and environmental samples has been the subject of many investigations [1-3], due to their impact on the environment, refining processes, and product quality. However, success is often hindered by the number and low concentration of these compounds in such samples, as well as by the lack of standards. Gas chromatography (GC) and GC coupled with electron ionization (EI) mass spectrometry (GC/ MS) are normally employed for samples containing robust, thermally stable analytes [4,5]. Atmospheric pressure ionization methods [6] - electrospray ionization (ESI) [7], atmospheric pressure chemical ionization (APCI) [8], and atmospheric pressure photoionization (APPI) [9]—in conjunction with liquid chromatography (LC) have been used for samples of more problematic analytes.

It is generally believed that ESI suffers more from nonlinear response and matrix effects than APCI. Linear response over a wide concentration range is an attractive feature of APCI and has been reported by several authors [10, 11]. Recently, Roussis and Fedora compared the ability of APCI and ESI to quantify polar

Address reprint requests to Dr. L. Ramaley, Trace Analysis Research Centre, Department of Chemistry, Dalhousie University, Halifax, NS, Canada B3H 4J3. E-mail: louis.ramaley@dal.ca

* Current address: Institute for Marine Biosciences, National Research Council of Canada, 1411 Oxford St., Halifax, NS, Canada, B3H $3 Z 1$. and ionic compounds in petroleum products [12]. They obtained linear ranges of three orders of magnitude for both techniques, and higher sensitivity for ESI. However, the ESI response was nonlinear over the concentration range of interest, and they recommended the use of APCI for quantitative LC/MS applications.

In the course of a study of the application of APCI to the analysis of nitrogen- and particularly sulfurcontaining PACs in petroleum samples, we observed nonlinear responses and also interactions between analytes. This prompted us to undertake an examination of the use of APCI to quantify these compounds over a wide range in concentration and in the presence of similar compounds that may cause interference. Dibenzothiophene (DBT), carbazole (CAR), and fluoren-9-one (FLU) were chosen as model heteroaromatic compounds, and pyrene (PY) was selected as a model polycyclic aromatic hydrocarbon (PAH) commonly found in petroleum samples (Scheme 1). Acetonitrile $\left(\mathrm{CH}_{3} \mathrm{CN}\right)$ and methanol $\left(\mathrm{CH}_{3} \mathrm{OH}\right)$ were selected as typical LC solvents and toluene $\left(\mathrm{C}_{7} \mathrm{H}_{8}\right)$ was used as a solvent of low polarity and low ionization energy. Although these model compounds are associated with petroleum samples, the results of the study are generally applicable to the analysis of non- and semi-polar compounds by APCI MS.

Recently, several direct atmospheric pressure ionization and injection methods with characteristics similar to APCI-direct analysis in real time (DART) [13], 



Dibenzothiophene (DBT) $\mathrm{M}^{+\bullet} 184 \mathrm{~m} / \mathrm{z}$

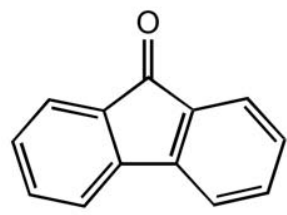

Fluoren-9-one (FLU) $\mathrm{M}^{+\bullet} 180 \mathrm{~m} / \mathrm{z}$

$$
\begin{gathered}
\text { Carbazole (CAR) } \\
\mathrm{M}^{+} 167 \mathrm{~m} / \mathrm{z}
\end{gathered}
$$<smiles></smiles>

Pyrene (PY) $\mathrm{M}^{+\bullet} 202 \mathrm{~m} / \mathrm{z}$

Scheme 1

atmospheric-pressure solids analysis probe (ASAP) [14], and plasma-assisted desorption/ionization (PADI) [15] - have been introduced. Although the mechanisms of ionization associated with these techniques [13-15], and with APPI [16, 17], are not necessarily the same as that of APCI, certain similarities do exist, and any information obtained regarding APCI may be helpful in understanding these other methods.

The objectives of the present work were threefold: (1) to determine analytical parameters such as detection limits, linear dynamic ranges, and the effect of solvent flow rate for model PACs in common LC solvents, (2) to study possible interferences between analytes, and (3) to examine the mechanisms of ionization in APCI of representative PACs.

\section{Experimental}

\section{Materials}

$\mathrm{CH}_{3} \mathrm{CN}, \mathrm{CH}_{3} \mathrm{OH}$, and $\mathrm{C}_{7} \mathrm{H}_{8}$ (HPLC grade, Fisher, Nepean, ON, Canada) were used as received. DBT, CAR, and FLU (Aldrich, Oakville, ON, Canada) were used without further purification. PY (Aldrich, Oakville, ON, Canada) was found to contain an impurity, which was removed by dissolving the $\mathrm{PY}$ in dichloromethane (Pesticide grade, Fisher, Nepean, ON, Canada) and extracting the impurity with $10 \%$ aqueous $\mathrm{HCl}$. After evaporation of the dichloromethane, PY was further purified by liquid chromatography using silica gel (60-100 mesh, $150 \AA$, Aldrich, Oakville, ON, Canada) as stationary phase and $\mathrm{C}_{7} \mathrm{H}_{8}$ as eluent. Nitrogen source gas was obtained by evaporation of liquid nitrogen generated in the Chemistry Department by membrane separation of nitrogen from air followed by liquefaction.

\section{Solutions}

Stock solutions of each PAC were prepared in $\mathrm{CH}_{3} \mathrm{CN}$ and in $\mathrm{CH}_{3} \mathrm{OH}$. Each stock solution was diluted with the same solvent to yield analytical solutions with concentrations in the range from $\sim 1 \times 10^{-8} \mathrm{~mol} \mathrm{~L}^{-1}$ to $\sim 1 \times 10^{-3} \mathrm{~mol} \mathrm{~L}^{-1}$ in $\mathrm{CH}_{3} \mathrm{CN}$ and from $\sim 4 \times 10^{-6} \mathrm{~mol}$ $\mathrm{L}^{-1}$ to $\sim 5 \times 10^{-2} \mathrm{~mol} \mathrm{~L}^{-1}$ in $\mathrm{CH}_{3} \mathrm{OH}$ for each PAC. Solutions of $\mathrm{PY}$ in $\mathrm{CH}_{3} \mathrm{OH}$ were prepared in the concentration range from $4 \times 10^{-6} \mathrm{~mol} \mathrm{~L}^{-1}$ to $2 \times 10^{-2} \mathrm{~mol}$ $\mathrm{L}^{-1}$, the solubility limit of PY.

Binary mixtures of PACs (DBT/PY, DBT/FLU, DBT/CAR) were prepared in $\mathrm{CH}_{3} \mathrm{CN}$ and in $\mathrm{CH}_{3} \mathrm{OH}$ to study the interactions of these compounds over a wide concentration range. In all experiments, the concentration of DBT was held constant and PY, CAR, or FLU were mixed with DBT to form solutions with final molar ratios (DBT:PAC) of 3:1, 1:1, and 1:3. For experiments at lower concentrations, the concentration of DBT was set to $1 \times 10^{-6} \mathrm{~mol} \mathrm{~L}^{-1}$ in $\mathrm{CH}_{3} \mathrm{CN}$ and $1 \times 10^{-4} \mathrm{~mol}$ $\mathrm{L}^{-1}$ in $\mathrm{CH}_{3} \mathrm{OH}$. For higher concentrations, the concentration of DBT was made $5 \times 10^{-4} \mathrm{~mol} \mathrm{~L}^{-1}$ in $\mathrm{CH}_{3} \mathrm{CN}$ and $1 \times 10^{-2} \mathrm{~mol} \mathrm{~L}^{-1}$ in $\mathrm{CH}_{3} \mathrm{OH}$. In the case of the DBT/PY mixture in $\mathrm{CH}_{3} \mathrm{OH}$, the concentration of DBT was $8 \times 10^{-3} \mathrm{~mol} \mathrm{~L}^{-1}$. In all cases, solutions of each PAC alone with a concentration that matched that of the PAC in the mixture were also prepared.

\section{Instrumentation and Procedures}

Mass spectra were obtained with a Micromass Quattro triple quadrupole mass spectrometer (Micromass UK Ltd., Manchester, UK) running under MassLynx ver. 3.5 software and equipped with a Micromass Quattro APCI source. The Quattro APCI source has been described in detail by Kolakowski et al. [18], and it is important to note that it is a closed source in which all gases and solvents are controlled. The corona discharge is not exposed to the atmosphere. The mass spectrometer was used in positive-ion APCI mode with nitrogen in all gas streams. Solvent ions rather than analyte ions were used to tune the mass spectrometer to avoid contamination of the instrument. Regular operating parameters (unless otherwise noted) were: corona voltage $=4.0 \mathrm{kV}$, cone voltage $=40 \mathrm{~V}(30 \mathrm{~V}$ for FLU and $50 \mathrm{~V}$ for PY), source temperature $=90^{\circ} \mathrm{C}$, and probe temperature $=$ $200^{\circ} \mathrm{C}$. Nitrogen flow was variable for each PAC: bath gas flow $=75-450 \mathrm{sLph}$ (standard liters per hour), sheath gas flow $=75-350 \mathrm{sLph}$, and nebulizer gas flow $=45 \mathrm{sLph}$.

Solutions were introduced into the APCI source by flow injection using a model 1100 binary pump (Agilent Technologies, Mississauga, ON, Canada) and a model 7125 Rheodyne injector (Supelco, Oakville, ON, Canada). Polyetheretherketone (PEEK) tubing (1/16 in. o.d.; Chromatographic Specialties, Brockville, ON, Canada) was used to make all tubing connections.

Limits of detection (LODs) and data for calibration curves were measured at solvent flow rates of 20, 100, 
and $500 \mu \mathrm{L} \mathrm{min}{ }^{-1}$ using sample loops of 20, 100, and $500 \mu \mathrm{L}$, respectively, both in $\mathrm{CH}_{3} \mathrm{CN}$ and in $\mathrm{CH}_{3} \mathrm{OH}$. The remaining studies (analysis of mixtures of PACs and determination of the total ion counts for each PAC in $\mathrm{CH}_{3} \mathrm{CN}, \mathrm{CH}_{3} \mathrm{OH}$, and $\mathrm{C}_{7} \mathrm{H}_{8}$ ) were carried out at 500

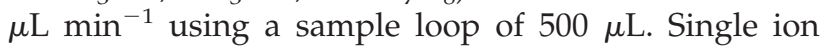
monitoring (SIM) was used for the determination of LODs, for the analysis of each PAC alone, and in mixtures of PACs. A dwell time of one second at the $\mathrm{m} / \mathrm{z}$ values of both the molecular ion and the protonated molecule for all PACs was employed. Full-scan data were also obtained for all the analyses $(30-250 \mathrm{~m} / \mathrm{z})$. Samples were injected after 25 scans of background were acquired, and data acquisition was continued until five scans after the total ion counts (TIC) had returned to the baseline. An average background was subtracted from the average analytical signal (five scans) and the responses (in counts) at the observed $\mathrm{m} / \mathrm{z}$ values were recorded.

The accurate mass of the impurity isolated from commercial pyrene was measured on a Consolidated Electrodynamics Corporation double-focusing magnetic sector mass spectrometer, model $21-110 \mathrm{~B}(\mathrm{EI}(+)$ at $70 \mathrm{eV}$ energy, probe temperature $=64{ }^{\circ} \mathrm{C}$, source temperature $=170^{\circ} \mathrm{C}$ ).

\section{Measurement of Corona Current}

The Quattro mass spectrometer employs an adjustable, controlled-voltage power supply to provide the corona discharge current. To measure this current it was necessary to place a $5000 \Omega$ resistor in series with the corona needle and measure the voltage across this resistor. This measurement was accomplished with a battery-powered, floating digital voltmeter (C-Ton Industries model DK500; Digi-Key Corp., Thief River Falls, MN) with a full-scale sensitivity of $200 \mathrm{mV}(40$ $\mu$ Amp by Ohm's law in terms of current) and an input impedance of $100 \mathrm{M} \Omega$.

\section{Theoretical Calculations}

Theoretical calculations for the $\Delta \mathrm{H}^{\circ}$ and the $\Delta \mathrm{G}^{\circ}$ values of the charge exchange and proton transfer reactions in $\mathrm{CH}_{3} \mathrm{OH}$ and $\mathrm{CH}_{3} \mathrm{CN}(\mathrm{T}=298.15 \mathrm{~K}$ and $P=1 \mathrm{~atm})$ were carried out using the Gaussian 03 suite of programs (Gaussian 2003) [19] on a Pentium 4 personal computer running under the Windows XP Professional operating system. The structures of neutral molecules and ions in the ground state were fully optimized using the B3LYP functional $[20,21]$ and the $6-31 \mathrm{G}(d)$ basis set. The B3LYP functional was selected because it yields accurate molecular geometries at moderate computational cost even for relatively large systems [22-25]. In spite of the limitations imposed by the use of small basis sets, we were obliged to use the $6-31 \mathrm{G}(d)$ basis set, since more extensive basis sets were not practical for systems of the size studied. While the B3LYP/6-31G(d) method would not be expected to predict as accurate thermochemical values for the systems investigated as more extensive basis sets on an absolute basis, it is adequate to predict trends in the $\Delta \mathrm{H}$ and $\Delta \mathrm{G}$ values (personal communication, Axel D. Becke, Department of Chemistry, Dalhousie University).

Vibrational frequencies were also computed to confirm that the optimized structures were at a minimum on the potential energy surface (no imaginary frequencies). In the case of $\mathrm{MH}^{+}$species, all possible isomers obtained by association of the proton with each carbon atom or heteroatom in the molecule were optimized to determine the preferred site of protonation for the model PACs.

Proton affinity (PA) values of the model PACs were estimated using the PBE1PBE/6-31+G(d)//B3LYP/ $6-31 G(d)$ level of theory. PBE1PBE is the generalizedgradient-approximation-exchange-correlation functional of Perdew et al. [26]. Proton affinity values were calculated as $\mathrm{PA}(\mathrm{M})=-\left(\mathrm{E}_{\mathrm{e}}\left(\mathrm{MH}^{+}\right)-\mathrm{E}_{\mathrm{e}}(\mathrm{M})+\mathrm{ZPE}\left(\mathrm{MH}^{+}\right)-\right.$ $\mathrm{ZPE}(\mathrm{M})-(5 / 2) \mathrm{RT})$, where $E_{\mathrm{e}}$ is the electronic energy and $\mathrm{ZPE}$ is the zero-point energy. ZPE values, obtained at the B3LYP/6-31G $(d)$ level, were scaled using a factor of 0.9806 as recommended by Scott and Radom [27]. The proton affinities of PACs similar to the model compounds were also calculated using the PBE1PBE/ $6-31+\mathrm{G}(d) / /$ B3LYP/6-31G $(d)$ level of theory to compare estimates with experimental values reported. The maximum deviations of the calculated proton affinities from the experimental values were $+0.10 \mathrm{eV}$ and $-0.15 \mathrm{eV}$. All calculations were performed with the default parameters of Gaussian 03.

\section{Results and Discussion}

\section{APCI Mass Spectra of Model PACs}

The intensities of the ions formed in the APCI source were dependent on solvent, cone voltage, gas, and solvent flow rates. Molecular ions, $\mathrm{M}^{+*}$, and protonated molecules, $\mathrm{MH}^{+}$, were both observed in the majority of the spectra. On the whole, the model PACs showed different abilities to ionize by either charge exchange or proton transfer. The relative abilities to ionize by proton transfer, given by the ratio $\mathrm{MH}^{+} /\left(\mathrm{MH}^{+}+\mathrm{M}^{+}\right)$, are shown in Table 1. A value of one indicates total ionization by proton transfer and zero indicates total charge exchange. The relative order is FLU $>$ CAR $>$ PY $>$ DBT. In all the results presented here the intensities of the $\mathrm{MH}^{+}$ions have been corrected for the contribution of the $[\mathrm{M}+1]^{+\cdot}$ peak.

Table 1. Efficiency of proton transfer versus charge exchange expressed as the ratio of ion counts $-\mathrm{MH}^{+} /\left(\mathrm{MH}^{+}+\mathrm{M}^{+}\right)-$for various solvents

\begin{tabular}{lccc}
\hline PAC & $\mathrm{C}_{7} \mathrm{H}_{8}$ & $\mathrm{CH}_{3} \mathrm{OH}$ & $\mathrm{CH}_{3} \mathrm{CN}$ \\
\hline \hline FLU & $0.99 \pm 0.08$ & $0.97 \pm 0.03$ & $0.91 \pm 0.13$ \\
CAR & $0.88 \pm 0.05$ & $0.53 \pm 0.05$ & $0.67 \pm 0.03$ \\
PY & $0.30 \pm 0.03$ & $0.48 \pm 0.04$ & 0.0 \\
DBT & $0.05 \pm 0.03$ & 0.0 & 0.0 \\
\hline
\end{tabular}




\section{Measurement of the Corona Needle Current}

A corona discharge occurs at the tip of a sharp needle when a high voltage is applied to the needle. The discharge is sustained by the production of ions in collisions of molecules with high-energy electrons in the high electric field near the tip of the needle $\left(\mathrm{M}+\mathrm{e}^{-} \rightarrow\right.$ $\mathrm{M}^{+}+2 \mathrm{e}^{-}$). In a positive corona discharge the electrons migrate to the needle. Mass spectrometers can control either the discharge current or the discharge voltage. The circuits in the Quattro maintain a constant discharge voltage. In either case, the current is a measure of the flow of electrons in the discharge and is indicative of the number of reagent ions formed in the source and available to produce analyte ions. The needle current was measured as a function of the needle voltage for three scenarios, (1) $\mathrm{N}_{2}$ alone, (2) $\mathrm{N}_{2}$ and solvent, and (3) $\mathrm{N}_{2}$, solvent, and analyte, to investigate the number of reagent ions available under these circumstances.

Needle current plots for $\mathrm{N}_{2}, \mathrm{CH}_{3} \mathrm{CN}, \mathrm{CH}_{3} \mathrm{OH}$, and $\mathrm{C}_{7} \mathrm{H}_{8}$ at a fixed nitrogen flow rate and a solvent flow rate of $500 \mu \mathrm{L} \mathrm{min}{ }^{-1}$ are shown in Figure 1. In general and as expected, the ionization current increases as the corona needle voltage increases, since the electrons are accelerated to higher velocities and the discharge sustaining ionization occurs more readily. The plots for lower solvent flow rates were similar in shape to those in Figure 1, but spaced even more closely together. Thus, at a given needle voltage and lower solvent flow rates, the currents and, therefore, the number of ions produced in the discharge are the same, regardless of solvent. At higher solvent flow rates, the current values diverge more, but the magnitudes of these deviations do not account for the large differences in relative ionization efficiency observed among solvents in the TIC studies (see below, Table 5).

The needle current was also measured in the presence of analyte using DBT as the test PAC. The presence of DBT had no effect, except for the case of the highest solvent flow rate, $500 \mu \mathrm{L} \mathrm{min}{ }^{-1}$, and relatively high

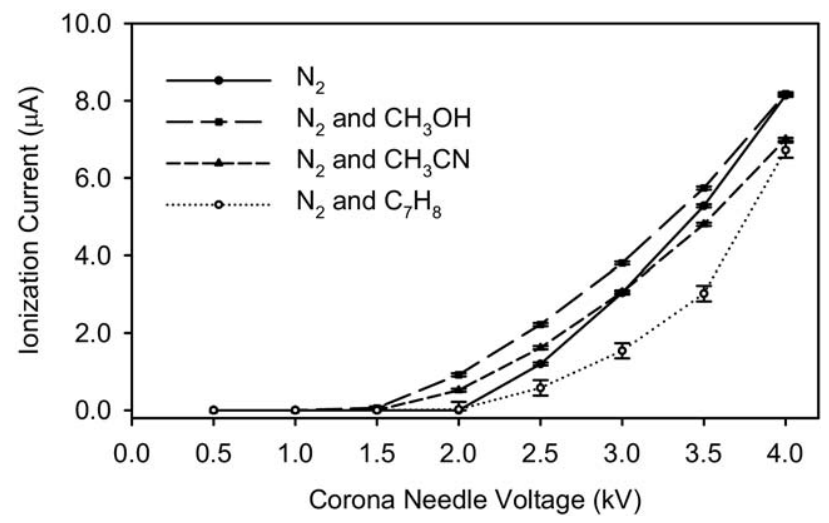

Figure 1. Corona needle current as a function of the needle voltage for $\mathrm{N}_{2}, \mathrm{CH}_{3} \mathrm{CN}, \mathrm{CH}_{3} \mathrm{OH}$, and $\mathrm{C}_{7} \mathrm{H}_{8}$ at $500 \mu \mathrm{L} \min ^{-1}$ solvent flow rate.
DBT concentrations, $\sim 2 \times 10^{-2} \mathrm{M}$, where the needle current was $5 \%$ to $20 \%$ lower than the current in the solvent alone. One possible explanation for this observation is that heavier $\mathrm{M}^{+\cdot}$ ions, such as those of the analyte, travel more slowly toward the counter electrode than lighter ions and, therefore, will stay longer in the vicinity of the corona needle. In this region, recombination of $\mathrm{M}^{+\cdot}$ may occur according to $\mathrm{M}^{+\cdot}+\mathrm{e}^{-} \rightarrow \mathrm{M}$, thus reducing the number of electrons that flows to the needle (the needle current). These results indicate that solvents and especially analytes have only minor effects on plasma generation and reagent ion numbers. Significant differences in analyte ionization efficiency must arise through channels other than variations in plasma generation.

\section{Limits of Detection}

Limits of detection (LOD, taken here as the concentration of analyte that produces a signal of twice $( \pm 0.2, n=5)$ the background) and linear ranges of response of the model PACs in $\mathrm{CH}_{3} \mathrm{CN}$ and $\mathrm{CH}_{3} \mathrm{OH}$ are listed in Table 2. The LODs are the lower values in the linear response ranges. In $\mathrm{CH}_{3} \mathrm{CN}$, the source gas flow rates and the cone voltage were varied until the best signal-to-noise ratio for a given PAC was obtained and optimal conditions were somewhat different for all PACs at the three solvent flow rates. In $\mathrm{CH}_{3} \mathrm{OH}$, however, limits of detection were determined using the same experimental conditions for all PACs to study the effect of the solvent flow rate on the LOD.

In $\mathrm{CH}_{3} \mathrm{CN}$ LODs decreased (improved) as solvent flow rate increased, and this applied both to $\mathrm{M}^{+\cdot}$ and $\mathrm{MH}^{+}$species. In $\mathrm{CH}_{3} \mathrm{OH}$, LODs decreased as solvent flow rate increased for the $\mathrm{M}^{+\cdot}$ of DBT and the opposite trend was observed for PACs that form predominantly $\mathrm{MH}^{+}$(CAR, PY, and FLU).

Under the conditions used, LODs in $\mathrm{CH}_{3} \mathrm{CN}$ are much lower, and thus better, than in $\mathrm{CH}_{3} \mathrm{OH}$. In general, LODs in $\mathrm{CH}_{3} \mathrm{OH}$ were not affected to a large extent, less than a factor of 2 , when the cone voltage or the gas flow rates were varied. Under the same experimental conditions, the noise levels in the spectra taken in $\mathrm{CH}_{3} \mathrm{OH}$ and in $\mathrm{CH}_{3} \mathrm{CN}$ were very similar. This indicates that the ionization efficiency of the model PACs (taken as the sum of the ion counts of the $\mathrm{M}^{+\cdot}$ and $\mathrm{MH}^{+}$ions) is lower in $\mathrm{CH}_{3} \mathrm{OH}$ than in $\mathrm{CH}_{3} \mathrm{CN}$, as discussed later.

\section{Linear Dynamic Range}

Calibration curves for the model PACs were obtained in both $\mathrm{CH}_{3} \mathrm{CN}$ and $\mathrm{CH}_{3} \mathrm{OH}$ to determine the linear range of response of the different analytes (Table 2). The upper concentration limit for the linear range was taken as the value for which, when the next higher concentration was included in the linear least-squares fitting, a clear decrease in the slope was observed. Linear ranges of at least three orders of magnitude, starting at the 




limits of detection, were obtained in $\mathrm{CH}_{3} \mathrm{CN}$. In many cases, the response could be considered almost linear well above the upper limits listed. In $\mathrm{CH}_{3} \mathrm{OH}$, linear ranges of three orders of magnitude or less were observed. In general, linear ranges extended to higher concentrations in $\mathrm{CH}_{3} \mathrm{OH}$ than in $\mathrm{CH}_{3} \mathrm{CN}$.

All model PACs displayed linear response at low concentrations (not shown) and negative deviations at high concentrations (Figure 2). This behavior is consistent with a model that postulates that a maximum (limiting) number of reagent ions are formed in the corona discharge. For low concentrations of analyte, a relatively large number of reagent ions are available to ionize the analyte and ion counts will increase linearly with analyte concentration. However, at some critical concentration, the analyte will begin to consume a significant fraction of the available reagent ions, causing a decrease in reagent ion concentration, nonlinear response, and even saturation.

The linear range extended to higher concentrations at lower solvent flow rates. This can be explained simply as an effect of analyte concentration in the ion source. If gas flow rate is held constant, the concentrations of both analyte and solvent molecules in the ion source should be directly proportional to solvent flow rate, providing more analyte molecules in the ion source at higher solvent flow rates. Since the number of reagent ions that form in the corona discharge is very similar at different solvent flow rates (see above), the concentration at which nonlinearity begins will be reached sooner at higher solvent flow rates.

To study the effect of the probe temperature on the analyte signal, calibration curves were measured using probe temperatures of 200,350 , and $450{ }^{\circ} \mathrm{C}$. At probe temperatures higher than $200^{\circ} \mathrm{C}$, the ion counts for the $\mathrm{M}^{+\cdot}$ and $\mathrm{MH}^{+}$species increased, however, the linear range of response did not extend to higher concentrations. These results are expected since vaporization of analyte and solvent molecules is more efficient at higher probe temperatures and the ion counts for $\mathrm{M}^{+\cdot}$ and $\mathrm{MH}^{+}$species will increase with the increase of mole-

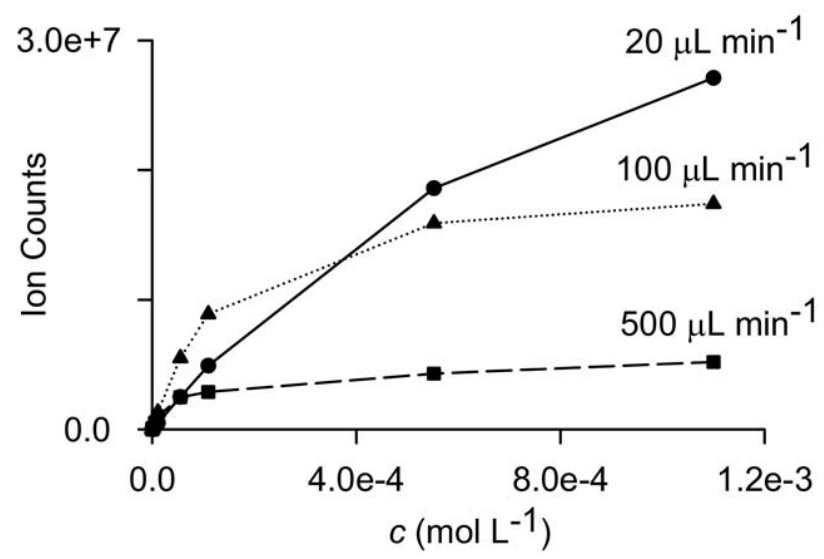

Figure 2. Representative calibration curves for $\mathrm{DBT}$ in $\mathrm{CH}_{3} \mathrm{CN}$ at various solvent flow rates in the nonlinear response region. 
Table 3. Mixture ion currents for DBT as \% of ion currents for DBT alone

\begin{tabular}{|c|c|c|c|c|c|c|c|}
\hline \multirow[b]{2}{*}{ PAC } & \multirow[b]{2}{*}{ [DBT $^{\mathrm{a}}$} & \multicolumn{2}{|c|}{ DBT:PAC - 3:1 } & \multicolumn{2}{|c|}{ DBT:PAC - 1:1 } & \multicolumn{2}{|c|}{ DBT:PAC - 1:3 } \\
\hline & & $\mathrm{CH}_{3} \mathrm{CN}$ & $\mathrm{CH}_{3} \mathrm{OH}$ & $\mathrm{CH}_{3} \mathrm{CN}$ & $\mathrm{CH}_{3} \mathrm{OH}$ & $\mathrm{CH}_{3} \mathrm{CN}$ & $\mathrm{CH}_{3} \mathrm{OH}$ \\
\hline \multirow[t]{2}{*}{ PY } & Low & $101 \%$ & $95 \%$ & $101 \%$ & $78 \%$ & $98 \%$ & $66 \%$ \\
\hline & High & $44 \%$ & $64 \%$ & $14 \%$ & $45 \%$ & $2 \%$ & $33 \%$ \\
\hline \multirow[t]{2}{*}{ CAR } & Low & $102 \%$ & $96 \%$ & $98 \%$ & $78 \%$ & $96 \%$ & $63 \%$ \\
\hline & High & $30 \%$ & $57 \%$ & $6 \%$ & $45 \%$ & $2 \%$ & $38 \%$ \\
\hline \multirow[t]{2}{*}{ FLU } & Low & $97 \%$ & $99 \%$ & $98 \%$ & $99 \%$ & $97 \%$ & $105 \%$ \\
\hline & High & $97 \%$ & $91 \%$ & $94 \%$ & $76 \%$ & $85 \%$ & $63 \%$ \\
\hline
\end{tabular}

a Low: $1 \times 10^{-6} \mathrm{M}$ in $\mathrm{CH}_{3} \mathrm{CN}, 1 \times 10^{-4} \mathrm{M}$ in $\mathrm{CH}_{3} \mathrm{OH}$; high $1 \times 10^{-4} \mathrm{M}$ in $\mathrm{CH}_{3} \mathrm{CN}, 1 \times 10^{-2} \mathrm{M}$ in $\mathrm{CH}_{3} \mathrm{OH}$ except $8 \times 10^{-3} \mathrm{M}$ for $\mathrm{PY}$.

cules in the vapor phase. However, an increase in the number of molecules in the ion source would cause the analyte signal to saturate sooner, giving no improvement in linearity.

\section{Study of mixtures of PACs}

Mixture studies were undertaken when it was observed that the signal for DBT decreased when increasing amounts of PY were added to mixtures of the two compounds (the concentrations of both PACs were sufficiently high to be in the nonlinear portion of the calibration curves). To determine the effect of different compounds on each other, two-component mixtures were examined.

The effects of adding various amounts of PY, CAR, and FLU in $\mathrm{CH}_{3} \mathrm{CN}$ and in $\mathrm{CH}_{3} \mathrm{OH}$ on the signal for DBT are shown in Table 3 . The values reported in the table were calculated according to eq 1 (the concentration of DBT alone and in the mixtures was the same).

Percent mixture current

$$
=\frac{\text { Ion counts for } \mathrm{M}^{+\cdot} \text { of DBT in mixture }}{\text { Ion counts for } \mathrm{M}^{+\cdot} \text { of DBT alone }} \times 100
$$

The results in $\mathrm{CH}_{3} \mathrm{CN}$ are more clear-cut than those in $\mathrm{CH}_{3} \mathrm{OH}$, but the trends in both solvents are the same. In $\mathrm{CH}_{3} \mathrm{CN}$, almost no interactions were observed in the linear response region and serious interactions were observed in the nonlinear region. In $\mathrm{CH}_{3} \mathrm{OH}$, interference (compared with $\mathrm{CH}_{3} \mathrm{CN}$ ) was greater in the linear region and not as serious in the nonlinear region, but there was still greater interference in the nonlinear region.

Two (or more) analytes present simultaneously in the ion source will compete for the limited number of reagent ions (see above). In the linear response region, a large number of reagent ions relative to analyte molecules are available and there is very little or no interference between analytes. In the nonlinear region, the analyte molecules must compete for reagent ions and interference will be observed. In the nonlinear regions the sum of the ion counts of the two analytes was approximately equal to that of one analyte alone. An example of this behavior, which is explained by the same model that explains the nonlinearity in the calibration curves above, is shown in Supplementary Figure 1 , which can be found in the electronic version of this article.

In terms of the ability to compete, both PY and CAR in $\mathrm{CH}_{3} \mathrm{CN}$ and $\mathrm{CH}_{3} \mathrm{OH}$ were more successful than DBT in reacting with reagent ions. FLU (which is ionized mainly by proton transfer while DBT is ionized by charge exchange) appeared less able to compete with DBT. Ionization energy data, Table 4, are consistent with the expected order of ease of charge exchange: PY[7.41] < CAR[7.50] < DBT[8.01] < FLU[8.29], where the values in brackets are the ionization energies (IE) in $\mathrm{eV}$. The effect on the signals of the other PACs when adding DBT was also studied; there was universally no effect observed at the low concentration ranges, and very little effect, less than $5 \%$, noted at the higher concentrations ranges either.

\section{Total Ion Current Studies}

In an attempt to test the idea that charge exchange efficiency was related to solvent $\mathrm{IE}, \mathrm{C}_{7} \mathrm{H}_{8}$ was introduced as a solvent with a lower IE than either $\mathrm{CH}_{3} \mathrm{OH}$ or $\mathrm{CH}_{3} \mathrm{CN}$. If solvent IE (see Table 4) were the controlling factor, the order of charge exchange efficiency

Table 4. Ionization properties of PAC analytes, solvents and gases

\begin{tabular}{lccc}
\hline Species & $\begin{array}{c}\text { Ionization } \\
\text { energy }^{\mathrm{a}} \\
\text { (IE) }(\mathrm{eV})\end{array}$ & $\begin{array}{c}\text { Proton affinity } \\
(\mathrm{PA})(\mathrm{eV})\end{array}$ & $\begin{array}{c}\text { Dissociation Energy } \\
{\text { of } \mathrm{C}_{\text {sp3 }}-\mathrm{H} \text { bonds }}^{\mathrm{e}} \\
D(\mathrm{~S}-\mathrm{H})(\mathrm{eV})\end{array}$ \\
\hline \hline $\mathrm{PY}$ & 7.41 & $9.01^{\mathrm{b}} / 9.14^{\mathrm{c}}$ & - \\
$\mathrm{CAR}$ & 7.50 & $9.05^{\mathrm{c}}$ & - \\
$\mathrm{FLU}$ & 8.29 & $8.98^{\mathrm{c}}$ & - \\
$\mathrm{DBT}$ & 8.01 & $8.56^{\mathrm{c}}$ & - \\
$\mathrm{C}_{7} \mathrm{H}_{8}$ & 8.83 & $8.13^{\mathrm{b} / 8.28^{\mathrm{c}}}$ & 3.8 \\
$\mathrm{CH}_{3} \mathrm{OH}$ & 10.85 & $7.82^{\mathrm{b}} / 7.72^{\mathrm{c}}$ & 4.2 \\
$\mathrm{CH}_{3} \mathrm{CN}$ & 12.20 & $8.08^{\mathrm{b}} / 8.08^{\mathrm{c}}$ & 4.1 \\
$\mathrm{~N}_{2}$ & $15.58^{\mathrm{d}}$ & $5.12^{\mathrm{b}}$ & - \\
$\mathrm{H}_{2}$ & 13.61 & - & - \\
\hline
\end{tabular}

aRef. [28].

bRef. [29].

'Estimated using the PBE1PBE/6-31+G(d)//B3LYP/6-31G(d) level of theory.

${ }^{d}$ The recombination energy of $\mathrm{N}_{2}^{+\cdot}$ is $15.3 \mathrm{eV}$ [30].

eRef. [31]. 
Table 5. Individual ion counts and the TIC for model PACs $\left([\mathrm{PAC}]=1 \times 10^{-5} \mathrm{M}\right)$

\begin{tabular}{|c|c|c|c|c|c|c|c|c|c|}
\hline \multirow[b]{2}{*}{$\underline{\text { PAC }}$} & \multicolumn{3}{|c|}{$\mathrm{M}^{+}$} & \multicolumn{3}{|c|}{$\mathrm{MH}^{+}$} & \multicolumn{3}{|c|}{$\mathrm{TIC}$} \\
\hline & $\mathrm{CH}_{3} \mathrm{CN}$ & $\mathrm{CH}_{3} \mathrm{OH}$ & $\mathrm{C}_{7} \mathrm{H}_{6}$ & $\mathrm{CH}_{3} \mathrm{CN}$ & $\mathrm{CH}_{3} \mathrm{OH}$ & $\mathrm{C}_{7} \mathrm{H}_{6}$ & $\mathrm{CH}_{3} \mathrm{CN}$ & $\mathrm{CH}_{3} \mathrm{OH}$ & $\mathrm{C}_{7} \mathrm{H}_{6}$ \\
\hline $\mathrm{PY}$ & $9.0 \times 10^{5}$ & $1.4 \times 10^{3}$ & $1.1 \times 10^{7}$ & - & $1.3 \times 10^{3}$ & $4.6 \times 10^{6}$ & $9.0 \times 10^{5}$ & $2.7 \times 10^{3}$ & $1.6 \times 10^{7}$ \\
\hline CAR & $1.9 \times 10^{6}$ & $4.1 \times 10^{3}$ & $1.1 \times 10^{7}$ & $3.9 \times 10^{6}$ & $4.6 \times 10^{3}$ & $7.7 \times 10^{6}$ & $5.8 \times 10^{6}$ & $8.7 \times 10^{3}$ & $1.9 \times 10^{7}$ \\
\hline FLU & $2.1 \times 10^{5}$ & $2.9 \times 10^{3}$ & $1.5 \times 10^{5}$ & $2.0 \times 10^{6}$ & $9.7 \times 10^{4}$ & $1.9 \times 10^{7}$ & $2.2 \times 10^{6}$ & $1.0 \times 10^{5}$ & $1.9 \times 10^{7}$ \\
\hline DBT & $6.8 \times 10^{5}$ & $2.6 \times 10^{3}$ & $6.6 \times 10^{6}$ & - & - & $3.6 \times 10^{5}$ & $6.8 \times 10^{5}$ & $2.6 \times 10^{3}$ & $7.0 \times 10^{6}$ \\
\hline
\end{tabular}

should be $\mathrm{CH}_{3} \mathrm{CN}>\mathrm{CH}_{3} \mathrm{OH}>\mathrm{C}_{7} \mathrm{H}_{8}$. The actual order was $\mathrm{C}_{7} \mathrm{H}_{8}>\mathrm{CH}_{3} \mathrm{CN}>\mathrm{CH}_{3} \mathrm{OH}$. The relative ionization efficiencies, shown in Table 5, were determined in $\mathrm{CH}_{3} \mathrm{OH}, \mathrm{CH}_{3} \mathrm{CN}$, and $\mathrm{C}_{7} \mathrm{H}_{8}$ by measuring the total ion counts (TICs). The TIC values listed in this table correspond to the sum of the counts for the $\mathrm{M}^{+\cdot}$ and $\mathrm{MH}^{+}$ ions for each compound. The relative standard deviations for these values range from $1 \%$ to $14 \%$ with an average of $9 \%$.

Large differences exist in the ionization efficiency among solvents, both with regard to charge exchange and proton transfer. In general, the total ion counts $\left(\mathrm{M}^{+\cdot}+\right.$ $\mathrm{MH}^{+}$) for all analytes followed the order: $\mathrm{C}_{7} \mathrm{H}_{8}>$ $\mathrm{CH}_{3} \mathrm{CN}>\mathrm{CH}_{3} \mathrm{OH}$, and this order seemed to apply both to the formation of $\mathrm{M}^{+\cdot}$ (with the exception of FLU) and $\mathrm{MH}^{+}$(with the exception of PY).

To test the idea that addition of $\mathrm{C}_{7} \mathrm{H}_{8}$ to the other solvents might significantly improve ionization efficiency, different amounts of $\mathrm{C}_{7} \mathrm{H}_{8}$ were added (vol/vol $2.5 \%, 5 \%$, and $10 \%)$ to solutions of DBT $\left(4 \times 10^{-5} \mathrm{~mol}\right.$ $\mathrm{L}^{-1}$ ) in $\mathrm{CH}_{3} \mathrm{OH}$. The addition of $\mathrm{C}_{7} \mathrm{H}_{8}$ provided only small improvements in the total ion counts for the $\mathrm{M}^{+}$. of DBT, which increased 2 times $\left(2.5 \% \mathrm{C}_{7} \mathrm{H}_{8}\right), 2.5$ times $\left(5 \% \mathrm{C}_{7} \mathrm{H}_{8}\right)$, and 4 times $\left(10 \% \mathrm{C}_{7} \mathrm{H}_{8}\right)$.

\section{Ionization Mechanisms for APCI}

Several factors make investigation of the mechanism of ionization for the model compounds in APCI difficult. Both molecular ions, $\mathrm{M}^{+}$, and protonated molecules, $\mathrm{MH}^{+}$, are often observed, indicating that there are at least two mechanisms for ionization, one or more involving charge exchange, and one or more involving proton transfer or hydrogen atom abstraction. Assuming that there is a limited number of primary nonprotonated ions formed in the discharge as indicated by the results above, the number of analyte ions formed by charge exchange will depend on the mechanisms available to form ions of all types, not just on the energetics of simple charge exchange.

A second complication is that the ions in and near the corona discharge cannot be observed with the mass spectrometer used in this study, since the distance from the corona needle to the high vacuum aperture of the analyzer is fixed and is relatively large (about $5 \mathrm{~cm}$ ). Any high-energy intermediate species will have reacted over this distance and, thus, only the lower energy ions that survive this journey will be detected. Protonated solvent molecules and ion clusters (the latter becoming intense at low cone voltages) were the only major higher-energy species observed in the background spectra of $\mathrm{CH}_{3} \mathrm{CN}$ and $\mathrm{CH}_{3} \mathrm{OH}$, while the ion counts for solvent radical cations were very low, less than $5 \%$. $\mathrm{C}_{7} \mathrm{H}_{8}$ is a special case, since the major peak observed in its mass spectrum was $m / z 91,\left[\mathrm{C}_{7} \mathrm{H}_{8}-\mathrm{H}\right]^{+}$, with other significant peaks at $m / z 105,77,79$, and 65 , indicating fragmentation, addition and, perhaps, rearrangement reactions in the plasma. Typical background spectra for our instrument are shown in Supplementary Figure 2.

\section{Formation of Reagent Ions}

In the following discussion, $\mathrm{N}_{2}$ will represent the source gas, A the analyte, and $S$ the solvent. If it is assumed that primary ion formation occurs in a very small volume at the corona needle tip and that collisions are energetic enough to ionize any molecule within that volume, the ions will be formed directly in proportion to their concentration. Even at the highest flow rate used for $\mathrm{CH}_{3} \mathrm{OH}$, there are 25 times as many $\mathrm{N}_{2}$ molecules present as $\mathrm{S}$ molecules and $7 \times 10^{6}$ times as many $\mathrm{N}_{2}$ molecules as $\mathrm{A}$ molecules (for an analyte concentration of $1 \times 10^{-5} \mathrm{M}$ and a total gas flow rate of $500 \mathrm{sLph}$ ). Thus the major source of primary ions will be $\mathrm{N}_{2}$ gas and the major primary ion will be $\mathrm{N}_{2}{ }^{+\cdot}$, Reaction (2) (even though the ionization energy of $\mathrm{N}_{2}$ is higher than that of A or S); $\mathrm{N}_{2}^{+\cdot}$ may undergo ion/molecule reactions to produce $\mathrm{N}_{4}{ }^{+}$, Reaction (3), as previously suggested [32-34].

$$
\begin{aligned}
& \mathrm{N}_{2}+\mathrm{e}^{-} \rightarrow \mathrm{N}_{2}^{+\cdot}+2 \mathrm{e}^{-} \\
& \mathrm{N}_{2}^{+\cdot}+\mathrm{N}_{2} \rightarrow \mathrm{N}_{4}^{+\cdot}
\end{aligned}
$$

Therefore, it is reasonable to assume that the next step in forming the ions actually observed in a mass spectrum is charge exchange to a solvent ion:

$$
\begin{aligned}
& \mathrm{N}_{2}^{+\cdot}+\mathrm{S} \rightarrow \mathrm{N}_{2}+\mathrm{S}^{+\cdot} \\
& \mathrm{N}_{4}^{+\cdot}+\mathrm{S} \rightarrow 2 \mathrm{~N}_{2}+\mathrm{S}^{+\cdot}
\end{aligned}
$$

Reactions (4) and (5) must be very rapid and strongly exothermic since neither $\mathrm{N}_{2}^{+\cdot}$ nor $\mathrm{N}_{4}^{+\cdot}$ were observed in any spectrum nor did Horning and coworkers observe such ions in spectra taken with a source in which the corona needle was separated by $4 \mathrm{~mm}$ or more from the analyzer entrance aperture [35]. Using the data in 
Table 6. $\Delta \mathrm{H}$ values from experimental data in $\mathrm{eV}$ for reactions that form $\mathrm{A}^{+}$

\begin{tabular}{|c|c|c|c|c|c|c|c|c|c|}
\hline \multirow[b]{2}{*}{ PAC } & \multicolumn{3}{|c|}{ Reaction (9) } & \multicolumn{3}{|c|}{ Reaction (10) } & \multicolumn{3}{|c|}{ Reaction (11) } \\
\hline & $\mathrm{CH}_{3} \mathrm{OH}$ & $\mathrm{CH}_{3} \mathrm{CN}$ & $\mathrm{C}_{7} \mathrm{H}_{8}$ & $\mathrm{CH}_{3} \mathrm{OH}$ & $\mathrm{CH}_{3} \mathrm{CN}$ & $\mathrm{C}_{7} \mathrm{H}_{8}$ & $\mathrm{CH}_{3} \mathrm{OH}$ & $\mathrm{CH}_{3} \mathrm{CN}$ & $\mathrm{C}_{7} \mathrm{H}_{8}$ \\
\hline PY & +1.63 & +1.89 & +1.94 & -1.25 & -1.15 & -0.85 & -3.44 & -4.79 & -1.42 \\
\hline CAR & +1.72 & +1.98 & +2.03 & -1.25 & -1.15 & -0.85 & -3.35 & -4.70 & -1.33 \\
\hline DBT & +2.23 & +2.49 & +2.54 & -1.23 & -1.13 & -0.83 & -2.84 & -4.19 & -0.82 \\
\hline FLU & +2.51 & +2.77 & +2.82 & -0.53 & -0.43 & -0.13 & -2.56 & -3.91 & -0.54 \\
\hline
\end{tabular}

Table 4 and considering that $\Delta \mathrm{H}=\mathrm{IE}(\mathrm{S})-\mathrm{RE}\left(\mathrm{N}_{2}{ }^{+}\right)$, where $\mathrm{RE}$ is the recombination energy, the $\Delta \mathrm{H}$ values for Reaction (4) are (in eV): -6.47 for $\mathrm{C}_{7} \mathrm{H}_{8},-4.45$ for $\mathrm{CH}_{3} \mathrm{OH}$, and -3.10 for $\mathrm{CH}_{3} \mathrm{CN}$.

To determine if the interaction of $\mathrm{N}_{4}^{+\cdot}$ with a solvent molecule leads to charge exchange, the $\Delta \mathrm{H}^{\circ}$ for Reaction (5) was estimated using density functional theory at the B3LYP/6-31G $(d)$ level. Calculated $\Delta \mathrm{H}^{\circ}$ values (in $\mathrm{eV})$ for Reaction (5) are: -5.5 for $\mathrm{C}_{7} \mathrm{H}_{8},-3.5$ for $\mathrm{CH}_{3} \mathrm{OH}$, and -2.2 for $\mathrm{CH}_{3} \mathrm{CN}$. (Calculated $\Delta \mathrm{H}^{\circ}$ values with the B3LYP/6-31G $(d)$ method for Reaction (4) are $0.9 \mathrm{eV}$ more negative than the experimental ones: -7.4 for $\mathrm{C}_{7} \mathrm{H}_{8},-5.4$ for $\mathrm{CH}_{3} \mathrm{OH}$, and -4.0 for $\mathrm{CH}_{3} \mathrm{CN}$, in eV). All the evidence presented by Harrison [36] indicates that such ion/molecule reactions are quite fast, and the calculations show that Reactions (4) and (5) are energetically favored for all solvent molecules $\left(\mathrm{C}_{7} \mathrm{H}_{8}>\right.$ $\mathrm{CH}_{3} \mathrm{OH}>\mathrm{CH}_{3} \mathrm{CN}$ ). Therefore, these high-energy nitrogen ions are probably consumed by Reactions (4) and (5) before having a chance to ionize the analyte.

Positive radical ions of the solvent can ionize other species present in the ion source by charge exchange. Given the higher concentration of solvent molecules compared with analyte molecules, $\mathrm{S}^{+\cdot}$ will probably also react with other solvent molecules by hydrogen atom abstraction, Reaction (6).

$$
\mathrm{S}^{+\cdot}+\mathrm{S} \rightarrow \mathrm{SH}^{+}+[\mathrm{S}-\mathrm{H}]^{\cdot}
$$

The $\Delta \mathrm{H}$ values (in $\mathrm{eV}$ ) for Reaction (6), considering that $\Delta \mathrm{H}=\mathrm{D}(\mathrm{S}-\mathrm{H})-\mathrm{PA}(\mathrm{S})+\mathrm{IE}(\mathrm{H})-\mathrm{IE}(\mathrm{S})$ are -2.59 in $\mathrm{CH}_{3} \mathrm{CN},-0.87$ in $\mathrm{CH}_{3} \mathrm{OH}$, and +0.43 in $\mathrm{C}_{7} \mathrm{H}_{8}$, where $D(\mathrm{~S}-\mathrm{H})$ is the carbon-hydrogen bond dissociation energy. Protonated solvent molecules should most easily form in $\mathrm{CH}_{3} \mathrm{CN}$ and with most difficulty in $\mathrm{C}_{7} \mathrm{H}_{8}$. This could explain why mostly $\mathrm{SH}^{+}$ions, and not $\mathrm{S}^{+\cdot}$ ions, are observed in the background spectra of $\mathrm{CH}_{3} \mathrm{CN}$ and $\mathrm{CH}_{3} \mathrm{OH}$.

\section{Formation of Analyte Molecular Ions, $A^{+}$.}

To this point we have discussed the formation of primary $\left(\mathrm{N}_{2}{ }^{+\cdot}\right.$ and $\left.\mathrm{N}_{4}^{+\cdot}\right)$ and secondary $\left(\mathrm{S}^{+\cdot}\right.$ and $\left.\mathrm{SH}^{+}\right)$ reagent ions. In the following section, some possible pathways for the formation of the analyte ions, $\mathrm{A}^{+\cdot}$ and $\mathrm{AH}^{+}$, will be reviewed, there being at least five possible paths leading to the formation of $\mathrm{A}^{+}$:
Direct ionization in the discharge :

$\mathrm{A}+\mathrm{e}^{-} \rightarrow \mathrm{A}^{+\cdot}+2 \mathrm{e}^{-}$

Charge exchange with a high-energy nitrogen ion:

$\mathrm{A}+\mathrm{N}_{2}^{+\cdot} \rightarrow \mathrm{A}^{+\cdot}+\mathrm{N}_{2}$

Charge exchange with $\mathrm{SH}^{+}$:

$\mathrm{A}+\mathrm{SH}^{+} \rightarrow \mathrm{A}^{+\cdot}+\mathrm{S}+\mathrm{H}$

Hydrogen atom abstraction from $\mathrm{AH}^{+}$:

$\mathrm{AH}^{+}+[\mathrm{S}-\mathrm{H}] \rightarrow \mathrm{A}^{+\cdot}+\mathrm{S}$

Charge exchange with $\mathrm{S}^{+\cdot}$ :

$\mathrm{A}+\mathrm{S}^{+\cdot} \rightarrow \mathrm{A}^{+\cdot}+\mathrm{S}$

The observation that ionization efficiency differs markedly among solvents argues against both significant amounts of direct analyte ionization in the discharge, Reaction (7), or analyte ionization by collision with a high-energy nitrogen ion, Reaction (8), even though such ionization is highly energetically favored. If either were the case, analyte ionization would be independent of solvent. Therefore, Reactions (7) and (8) can be eliminated from consideration as major sources of $\mathrm{A}^{+.}$.

Formation of $\mathrm{A}^{+\cdot}$ must thus proceed through some higher-energy solvent species $\left(\mathrm{S}^{+\cdot}\right.$ or $\left.\mathrm{SH}^{+}\right)$. To determine if $\mathrm{SH}^{+}$ions are able to ionize the analyte by charge exchange, $\Delta \mathrm{H}$ values for Reaction (9) were calculated considering that $\Delta \mathrm{H}=\mathrm{PA}(\mathrm{S})-\mathrm{IE}(\mathrm{H})+\mathrm{IE}(\mathrm{A})$ (Table 6). Reaction (9) is highly endothermic for all of the analytes in this study, with the most endothermic involving FLU in $\mathrm{C}_{7} \mathrm{H}_{8}(+2.82 \mathrm{eV})$ and the least involving PY in $\mathrm{CH}_{3} \mathrm{OH}(+1.63 \mathrm{eV})$. However, all $\Delta \mathrm{H}$ values for proton transfer via the pathway $\mathrm{A}+\mathrm{SH}^{+} \rightarrow \mathrm{AH}^{+}+\mathrm{S}$ are exothermic (details in Table 7). Therefore, it is more likely that when an analyte molecule collides with a protonated solvent molecule, proton transfer will take place. In addition, Reaction (9) would involve two discrete steps, making it an unlikely pathway for the formation of $\mathrm{A}^{+}$.

The radical cation of the analyte could also be formed by hydrogen atom abstraction from $\mathrm{AH}^{+}$by $[\mathrm{S}-\mathrm{H}]$ according to Reaction (10). The $\Delta \mathrm{H}$ values for Reaction (10) are exothermic $(\Delta \mathrm{H}=\mathrm{IE}(\mathrm{A})+\mathrm{PA}(\mathrm{A})-\mathrm{IE}(\mathrm{H})-$ $D(\mathrm{~S}-\mathrm{H}))$ (Table 6). For this path the order of decreasing reactivity with regard to solvent is $\mathrm{CH}_{3} \mathrm{OH}>\mathrm{CH}_{3} \mathrm{CN}>$ 
Table 7. $\Delta \mathrm{H}$ values from experimental data in $\mathrm{eV}$ for reactions that form $\mathrm{AH}^{+}$

\begin{tabular}{|c|c|c|c|c|c|c|c|c|c|}
\hline \multirow[b]{2}{*}{ PAC } & \multicolumn{3}{|c|}{ Reaction (12) } & \multicolumn{3}{|c|}{ Reaction (14) } & \multicolumn{3}{|c|}{ Reaction (15) } \\
\hline & $\mathrm{CH}_{3} \mathrm{OH}$ & $\mathrm{CH}_{3} \mathrm{CN}$ & $\mathrm{C}_{7} \mathrm{H}_{8}$ & $\mathrm{CH}_{3} \mathrm{OH}$ & $\mathrm{CH}_{3} \mathrm{CN}$ & $\mathrm{C}_{7} \mathrm{H}_{8}$ & $\mathrm{CH}_{3} \mathrm{OH}$ & $\mathrm{CH}_{3} \mathrm{CN}$ & $\mathrm{C}_{7} \mathrm{H}_{8}$ \\
\hline PY & +1.25 & +1.15 & +0.85 & -1.32 & -1.06 & -1.01 & -2.19 & -3.65 & -0.58 \\
\hline CAR & +1.25 & +1.15 & +0.85 & -1.23 & -0.97 & -0.92 & -2.10 & -3.56 & -0.49 \\
\hline FLU & +0.53 & +0.43 & +0.13 & -1.16 & -0.90 & -0.85 & -2.03 & -3.49 & -0.42 \\
\hline DBT & +1.23 & +1.13 & +0.83 & -0.74 & -0.48 & -0.43 & -1.61 & -3.07 & 0.00 \\
\hline
\end{tabular}

$\mathrm{C}_{7} \mathrm{H}_{8}$, the reverse of experimental observation, and with regard to analyte is $\mathrm{PY}=\mathrm{CAR}>\mathrm{DBT}>\mathrm{FLU}$, similar to experimental observation in $\mathrm{CH}_{3} \mathrm{CN}$ and $\mathrm{C}_{7} \mathrm{H}_{8}$, but less so in $\mathrm{CH}_{3} \mathrm{OH}$.

The $\Delta \mathrm{H}$ values for Reaction (11), see Table 6, can be calculated from $\Delta \mathrm{H}=\mathrm{IE}(\mathrm{A})-\operatorname{RE}\left(\mathrm{S}^{+\cdot}\right)$ (in the event $\mathrm{RE}\left(\mathrm{S}^{+}\right)$values are not known, $\mathrm{IE}(\mathrm{S})$ can be used as a reasonable approximation of $\operatorname{RE}\left(\mathrm{S}^{+}\right)$, realizing that $\mathrm{IE}(\mathrm{S})$ will be slightly higher than $\left.\mathrm{RE}\left(\mathrm{S}^{+\cdot}\right)\right)$. For a given solvent (IE(S) is constant), the order of ease of ionization of the analyte should decrease as IE(A) increases leading to the following order: $\mathrm{PY}>\mathrm{CAR}>\mathrm{DBT}>\mathrm{FLU}$ which is similar to the experimental order in $\mathrm{CH}_{3} \mathrm{CN}$ and $\mathrm{C}_{7} \mathrm{H}_{8}$, but different from the order observed in $\mathrm{CH}_{3} \mathrm{OH}$. For a given analyte (IE(A) is constant), the ability of $\mathrm{S}^{+\cdot}$ to undergo charge exchange with A should decrease as $\operatorname{IE}(\mathrm{S})$ decreases and the following order is obtained: $\mathrm{CH}_{3} \mathrm{CN}^{+\cdot}>\mathrm{CH}_{3} \mathrm{OH}^{+\cdot}>\mathrm{C}_{7} \mathrm{H}_{8}^{+\cdot}$, which does not agree with the experimental order.

Both Reaction (10) and (11) are energetically favored for all the analytes studied here. Since production of $\mathrm{A}^{+}$. via Reaction (10) requires that $A$ first must be converted to $\mathrm{AH}^{+}$and since Reaction (10) is much less energetically favored than Reaction (11), it is logical to assume that the major channel responsible for generation of $\mathrm{A}^{+}$. is charge exchange with $\mathrm{S}^{+}$, Reaction (11). If this reaction occurs rapidly, then all the solvents should provide approximately the same degree of analyte ionization - this is not observed. If, on the other hand, the extent of reaction is somehow limited by the energy available, then the expected order of ease of ionization by charge exchange should be: $\mathrm{CH}_{3} \mathrm{CN}[12.20]>$ $\mathrm{CH}_{3} \mathrm{OH}[10.85]>\mathrm{C}_{7} \mathrm{H}_{8}$ [8.83] (IEs in brackets in eV). This was the order observed for $\mathrm{CH}_{3} \mathrm{CN}$ and $\mathrm{CH}_{3} \mathrm{OH}$ early in the study. However, when $\mathrm{C}_{7} \mathrm{H}_{8}$ was examined in an attempt to test this hypothesis, the results showed that ionization was greatest in $\mathrm{C}_{7} \mathrm{H}_{8}$, not least. Thus, none of eqs (7-11) fully explains the experimental observations.

\section{Formation of Analyte Protonated Molecules, $\mathrm{AH}^{+}$}

There are at least four possible paths for the formation of $\mathrm{AH}^{+}$ions:

Hydrogen atom abstraction from S:

$$
\mathrm{A}^{+\cdot}+\mathrm{S} \rightarrow \mathrm{AH}^{+}+[\mathrm{S}-\mathrm{H}]
$$

Hydrogen exchange between $\mathrm{A}^{+\cdot}$ and $\mathrm{A}$ :

$$
\mathrm{A}^{+\cdot}+\mathrm{A} \rightarrow \mathrm{AH}^{+}+[\mathrm{A}-\mathrm{H}]
$$

Proton transfer from $\mathrm{SH}^{+}$:

$\mathrm{A}+\mathrm{SH}^{+} \rightarrow \mathrm{AH}^{+}+\mathrm{S}$

Proton transfer from $\mathrm{S}^{+\cdot}$ :

$$
\mathrm{A}+\mathrm{S}^{+\cdot} \rightarrow \mathrm{AH}^{+}+[\mathrm{S}-\mathrm{H}]
$$

The $\Delta \mathrm{H}$ values for Reaction (12) can be calculated using $\Delta \mathrm{H}=\mathrm{IE}(\mathrm{H})+D(\mathrm{~S}-\mathrm{H})-\mathrm{PA}(\mathrm{A})-\mathrm{IE}(\mathrm{A})$ (Table 7), and are endothermic for all combinations. This is the path proposed by Syage [16] to explain the presence of protonated molecules in the mass spectra of compounds ionized by APPI. For the solvents, the order of decreasing ability to undergo hydrogen atom abstraction is $\mathrm{C}_{7} \mathrm{H}_{8}>\mathrm{CH}_{3} \mathrm{CN}>\mathrm{CH}_{3} \mathrm{OH}$, which agrees with the experimental order except for PY, and for the model PACs the order is FLU $>\mathrm{DBT} \approx \mathrm{CAR}=\mathrm{PY}$, while the experimental order is FLU $>\mathrm{CAR}>\mathrm{PY}>\mathrm{DBT}$, except when the solvent is $\mathrm{CH}_{3} \mathrm{CN}$ (Table 5).

Production of $\mathrm{AH}^{+}$as described by Reaction (13) may occur either by transfer of $\mathrm{H}^{+}$from $\mathrm{A}^{+\cdot}$ to $\mathrm{A}$ or by transfer of an $\mathrm{H}$ atom from $\mathrm{A}$ to $\mathrm{A}^{+}$. In the calculation of $\Delta \mathrm{H}$ for Reaction (13), $\Delta \mathrm{H}=\mathrm{IE}(\mathrm{H})+D(\mathrm{~A}-\mathrm{H})-\mathrm{PA}(\mathrm{A})-\mathrm{IE}(\mathrm{A})$, the assumption that the $\mathrm{C}_{\mathrm{sp} 2}-\mathrm{H}$ bond dissociation energy in the analyte, $D(\mathrm{~A}-\mathrm{H})$, is equal to that of benzene $(4.9 \mathrm{eV})$ [31] was made. This thermochemical model, which does not depend on the solvent and thus does not explain the experimental observations, provides positive $\Delta \mathrm{H}$ values in all cases, the order of endothermicity being $(\Delta \mathrm{H}$ in brackets in $\mathrm{eV}):$ PY[1.95] $=$ CAR[1.95] $\approx$ DBT[1.93] $>$ FLU[1.23], which indicates that once $\mathrm{A}^{+\cdot}$ is formed, it is unlikely to become converted to $\mathrm{AH}^{+}$either by reacting with a solvent molecule, Reaction (12), or another analyte molecule, Reaction (13).

Protonated analyte molecules can be formed from $\mathrm{SH}^{+}$ by transfer of $\mathrm{H}^{+}$(Reaction (14)) and the $\Delta \mathrm{H}$ values can be calculated as $\Delta \mathrm{H}=\mathrm{PA}(\mathrm{S})-\mathrm{PA}(\mathrm{A})$ (Table 7). Reaction (14) is exothermic in all cases and is thus energetically favored. For a given solvent $(\mathrm{PA}(\mathrm{S})$ is constant), the order of ease of proton transfer should decrease as $\mathrm{PA}(\mathrm{A})$ decreases. This leads to the following order: PY $>$ CAR $>$ FLU $>$ DBT, different from the experimental trend. For a given analyte (PA(A) is constant), the ability of $\mathrm{SH}^{+}$to lose a proton should decrease as PA(S) increases, and therefore Reaction (14) is expected to be more highly favored in $\mathrm{CH}_{3} \mathrm{OH}$ and less so in $\mathrm{CH}_{3} \mathrm{CN}$ or $\mathrm{C}_{7} \mathrm{H}_{8}$, opposite to the order observed in the TIC studies. The above calculations assume that $\left[\mathrm{C}_{7} \mathrm{H}_{8}+\mathrm{H}\right]^{+}$is the reagent ion that would transfer a proton to an analyte molecule in a toluene-containing plasma. However, the chemistry of the ions in the plasma 
is probably more complex than portrayed by the above schemes, and this may be even more so for $\mathrm{C}_{7} \mathrm{H}_{8}$, where a range of ions is observed in the mass spectrum.

According to Reaction (15), protonated analyte molecules could be formed by transfer of $\mathrm{H}^{+}$from $\mathrm{S}^{+\cdot}$ to analyte molecules, where $\Delta \mathrm{H}=\mathrm{IE}(\mathrm{H})+D(\mathrm{~S}-\mathrm{H})-\mathrm{PA}(\mathrm{A})$ - IE(S); see Table 7. For this path, the reaction is exothermic for almost all PACs (except DBT in $\mathrm{C}_{7} \mathrm{H}_{8}$ ). For the solvents, the order of decreasing ability to transfer a proton is $\mathrm{CH}_{3} \mathrm{CN}>\mathrm{CH}_{3} \mathrm{OH}>\mathrm{C}_{7} \mathrm{H}_{8}$, and for the analytes the expected order is $\mathrm{PY}>\mathrm{CAR}>\mathrm{FLU}>\mathrm{DBT}$, which do not agree with the experimental order.

These results indicate that $\mathrm{A}^{+\cdot}$ is possibly formed via Reaction (11), while $\mathrm{AH}^{+}$may be formed by Reactions (14) and/or (15). However, the above thermochemical models do not explain the large effect of the solvent on the ionization process or the solvent order obtained in the total ion count studies. For all compounds, $\mathrm{C}_{7} \mathrm{H}_{8}$ provides the best medium for proton transfer with $\mathrm{CH}_{3} \mathrm{OH}$ providing a slight edge over $\mathrm{CH}_{3} \mathrm{CN}$ on a relative basis, but not on an absolute basis. In all cases except FLU, $\mathrm{C}_{7} \mathrm{H}_{8}$ also provides greater charge exchange ionization on an absolute basis. In general, the ion counts in $\mathrm{C}_{7} \mathrm{H}_{8}$ are an order of magnitude higher than in $\mathrm{CH}_{3} \mathrm{CN}$, and those in $\mathrm{CH}_{3} \mathrm{CN}$ are two orders of magnitude higher than in $\mathrm{CH}_{3} \mathrm{OH}$, and this is valid for both charge exchange and proton transfer.

\section{Effects of Solvation on the Ionization Process}

Kebarle and coworkers have pointed out that clustering (solvation) has a large effect on the sensitivities observed in an APCI experiment in which protonated water molecules were thought to be the reagent ions [34, 37]. These authors studied ionization mechanisms in APCI to explain the different sensitivities of nitrogen-, oxygen-, and sulfurcontaining bases to proton transfer and explained the sensitivity order observed as being due to differences in solvation energies and gas-phase basicities.

Since the present experimental results could not be rationalized by the preceding thermodynamic arguments, it seemed appropriate to investigate the effects of clustering under our conditions. Two possible types of solvent clusters are relevant, solvated molecular ions, $(\mathrm{S})_{\mathrm{n}} \mathrm{S}^{+*}$, and solvated protonated clusters, $(\mathrm{S})_{n} \mathrm{SH}^{+}$. Reactions (11), (14), and (15) involving charge exchange and proton transfer now become, respectively,

$$
\begin{aligned}
& \mathrm{A}+(\mathrm{S})_{\mathrm{n}} \mathrm{S}^{+\cdot} \rightarrow(\mathrm{S})_{\mathrm{n}+1-\mathrm{h}} \mathrm{A}^{+\cdot}+\mathrm{hS} \\
& \mathrm{A}+(\mathrm{S})_{\mathrm{n}} \mathrm{SH}^{+} \rightarrow(\mathrm{S})_{\mathrm{n}+1-\mathrm{h}} \mathrm{AH}^{+}+\mathrm{hS} \\
& \mathrm{A}+(\mathrm{S})_{\mathrm{n}} \mathrm{S}^{+\cdot} \rightarrow(\mathrm{S})_{\mathrm{n}-\mathrm{h}-\mathrm{i}} \mathrm{AH}^{+}+\mathrm{hS}+\mathrm{S}_{\mathrm{i}}[\mathrm{S}-\mathrm{H}]
\end{aligned}
$$

$\mathrm{C}_{7} \mathrm{H}_{8}$ is less polar than either $\mathrm{CH}_{3} \mathrm{CN}$ or $\mathrm{CH}_{3} \mathrm{OH}$; intermolecular interactions will be lower and, hence, the ions and ion clusters in $\mathrm{C}_{7} \mathrm{H}_{8}$ will probably not resemble those in $\mathrm{CH}_{3} \mathrm{CN}$ or $\mathrm{CH}_{3} \mathrm{OH}$. The effect of clustering on the energetics of these reactions will depend on the energetics of the simple reactions with- out solvation, the solvation bond strengths between solvent and the radicals or ions and on the values of $n$, $(n+1-h)$, and $(n-h-i)$, the number of bonds formed.

It reasonable to expect that solvation of solvent ions $\left(\mathrm{S}^{+\cdot}\right.$ and $\left.\mathrm{SH}^{+}\right)$would be highest in $\mathrm{CH}_{3} \mathrm{OH}$, where hydrogen bonding should be significant, and lowest in $\mathrm{C}_{7} \mathrm{H}_{8}$, with $\mathrm{CH}_{3} \mathrm{CN}$ being intermediate. In Reactions (16) to (18), an increase in solvation of the analyte ions (right hand sides) will favor the reactions proceeding as written, whereas an increase in solvation of the solvent ions (left hand sides) will disfavor these reactions. For analyte ions, both solvation energy and $(n+1-h)$ or $(n-h-i)$ are expected to follow the order: FLU $>$ CAR $>\mathrm{PY} \approx \mathrm{DBT}$, based on polarity and the ability to hydrogen bond. This is the order observed for relative ability to react in proton transfer (see Table 1) and it is also the general order observed in overall ion count. None of the analyte molecules is very polar, and none participates strongly in hydrogen bonding; however, FLU hydrogen bonds with protic solvents, but to an extent smaller than an alcohol. Note that the ion counts for FLU in $\mathrm{CH}_{3} \mathrm{OH}$ are much higher than those for the other analytes (Table 5), which could be due to a greater extent of solvation of $\mathrm{AH}^{+}$.

The above analysis suggests that the extent of solvation of solvent ions, which tends to hinder analyte ionization, should be greater in $\mathrm{CH}_{3} \mathrm{OH}$ than in $\mathrm{CH}_{3} \mathrm{CN}$, which in turn would be greater than in $\mathrm{C}_{7} \mathrm{H}_{8}$. This would explain the order observed in overall ionization efficiency. An increase in the extent of solvation of the analyte ion, as in the case of FLU, should lead to an increase in relative ionization efficiency. In the same manner, the solvent will affect the LOD of the model analytes (Table 2). LODs are lower in $\mathrm{CH}_{3} \mathrm{CN}$ than in $\mathrm{CH}_{3} \mathrm{OH}$, where the extent of solvation is expected to be higher. Furthermore, LODs for $\mathrm{MH}^{+}$species in $\mathrm{CH}_{3} \mathrm{OH}$ increase (worsen) with an increase in the solvent flow rate and thus an increase in solvent concentration in the ion source, which in turn will increase the extent of solvation of the solvent ions.

\section{Calculations to Support the Influence of Solvation}

In the absence of experimental thermodynamic data for analyte and solvent clusters and to obtain the $\Delta \mathrm{H}^{\circ}$ and $\Delta \mathrm{G}^{\circ}$ values for the charge exchange (16) and the proton transfer $(17,18)$ reactions when considering solvation, the enthalpy $(\mathrm{H})$ and Gibbs free-energy $(\mathrm{G})$ of $\mathrm{S}_{\mathrm{n}}(\mathrm{n}=1-3), \mathrm{A}$, $(\mathrm{S})_{\mathrm{n}} \mathrm{S}^{+\cdot}(\mathrm{n}=0-2),(\mathrm{S})_{\mathrm{n}} \mathrm{SH}^{+}(\mathrm{n}=0-2),(\mathrm{S})_{\mathrm{n}} \mathrm{A}^{+\cdot}(\mathrm{n}=0,1)$, $(\mathrm{S})_{\mathrm{n}} \mathrm{AH}^{+}(\mathrm{n}=0,1)$, and $\mathrm{S}_{\mathrm{n}}[\mathrm{S}-\mathrm{H}] \quad(\mathrm{n}=0,1)$ (where $\mathrm{A}$ represents DBT, PY, CAR, or FLU, and $S$ represents $\mathrm{CH}_{3} \mathrm{CN}$ or $\mathrm{CH}_{3} \mathrm{OH}$ ) were estimated using density functional theory. Thermodynamic data were calculated for the solvent clustering Reactions (19) to (22) in the gas phase, Table 8:

$$
\begin{aligned}
& (\mathrm{S})_{\mathrm{n}} \mathrm{SH}^{+}+\mathrm{S} \rightarrow(\mathrm{S})_{\mathrm{n}+1} \mathrm{SH}^{+}(\mathrm{n}=-1,0,1) \\
& (\mathrm{S})_{\mathrm{n}} \mathrm{S}^{+\cdot}+\mathrm{S} \rightarrow(\mathrm{S})_{\mathrm{n}+1} \mathrm{~S}^{+\cdot}(\mathrm{n}=0,1) \\
& {[\mathrm{S}-\mathrm{H}]+\mathrm{S} \rightarrow \mathrm{S}[\mathrm{S}-\mathrm{H}]}
\end{aligned}
$$


Table 8. Theoretical and experimental (in parentheses) thermodynamic data for the clustering reactions (19-22) where $\mathrm{S}$ is $\mathrm{CH}_{3} \mathrm{CN}$ or $\mathrm{CH}_{3} \mathrm{OH}\left(\Delta \mathrm{H}^{\circ}\right.$ and $\Delta \mathrm{G}^{\circ}$ in $\mathrm{eV}, \Delta \mathrm{S}^{\circ}$ in $\left.10^{3} \mathrm{eV} \mathrm{K}^{-1}\right)$

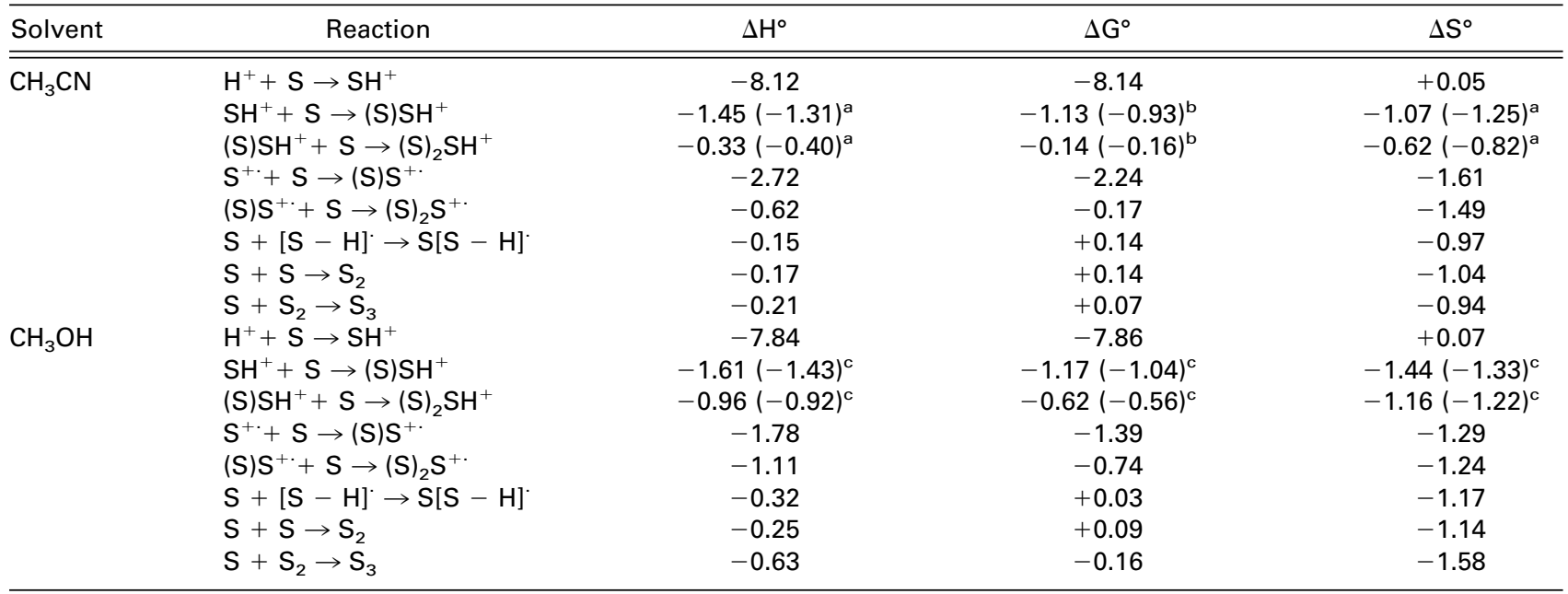

aRef. [38].

bValues estimated from $\Delta \mathrm{G}^{\circ}=\Delta \mathrm{H}^{\circ}-\mathrm{T} \Delta \mathrm{S}^{\circ}$ using $\Delta \mathrm{H}^{\circ}$ and $\Delta \mathrm{S}^{\circ}$ taken from [38].

${ }^{\text {'Ref. [39]. }}$

$$
\mathrm{S}_{\mathrm{n}}+\mathrm{S} \rightarrow \mathrm{S}_{\mathrm{n}+1}(\mathrm{n}=1,2)
$$

To assess the reliability of the theoretical calculations, the data for Reaction (19) are compared in Table 8 with available experimental values. Although overestimated in most cases, the calculated $\Delta \mathrm{H}^{\circ}$ values are in good agreement with the experimental ones. As indicated by their $\Delta \mathrm{H}^{\circ}$ and $\Delta \mathrm{G}^{\circ}$ values, all the clustering reactions involving ions are exothermic and spontaneous (under standard conditions), and for both $\mathrm{CH}_{3} \mathrm{CN}$ and $\mathrm{CH}_{3} \mathrm{OH}, \Delta \mathrm{H}^{\circ}$ and $\Delta \mathrm{G}^{\circ}$ become less favorable with increasing $\mathrm{n}$. The solvation of radicals and neutrals is, in general, less exothermic and in most cases nonspontaneous under standard conditions. The $\Delta \mathrm{G}^{\circ}$ values for the formation of solvated species indicate that $\mathrm{CH}_{3} \mathrm{OH}$ solvates more strongly than $\mathrm{CH}_{3} \mathrm{CN}$ beyond the first solvent molecule.

Thermodynamic data are presented in Table 9 for the charge exchange Reaction (16) and in Tables 10 and 11 for the proton transfer Reactions (17) and (18) involving analyte. In the tables, estimated $\Delta \mathrm{H}^{\circ}$ values for Reactions (11), (14), and (15) are compared with the $\Delta \mathrm{H}$ values calculated using experimental thermochemical data (Table 4). For Reaction (14), proton transfer, the theoretical values are consistently more negative than experimental ones with an average deviation of $-0.18 \mathrm{eV}$, while for Reaction (15), also proton transfer, the theoretical values are consistently less negative, with an average deviation of $+0.17 \mathrm{eV}$. For Reaction (11), charge exchange, the agreement between theory and experiment is better with both positive and negative deviations and an average deviation of $0.02 \mathrm{eV}$.

Overall, the calculations suggest that all reactions are exothermic and spontaneous for $\mathrm{n}=0$ and become less so with increasing $\mathrm{n}$. This indicates that the solvated reagent ions, $(\mathrm{S})_{n} \mathrm{SH}^{+}$or $(\mathrm{S})_{n} \mathrm{~S}^{+}$, will be less efficient than the bare ions, $\mathrm{SH}^{+}$or $\mathrm{S}^{+\cdot}$, in ionizing the analyte. In addition, when the products, $\mathrm{AH}^{+}$or $\mathrm{A}^{+\cdot}$, are solvated, the proton transfer and the charge exchange reactions become more exothermic as compared to the case of nonsolvated products.

When considering solvated as opposed to bare analyte ions, the calculations predict an exothermicity order similar to the relative ionization efficiency order obtained in the TIC studies. For both proton transfer reactions (in a given solvent) the order predicted by the calculations is FLU $>$ CAR $>$ PY $>$ DBT, with analyte solvation and $\mathrm{PY}>\mathrm{CAR}>\mathrm{FLU}>\mathrm{DBT}$ without solvation (both in $\mathrm{CH}_{3} \mathrm{CN}$ and $\mathrm{CH}_{3} \mathrm{OH}$ ). The orders observed in the experimental studies are FLU $>$ CAR $>$ $\mathrm{PY}>\mathrm{DBT}$ in $\mathrm{CH}_{3} \mathrm{OH}$ and $\mathrm{CAR}>\mathrm{FLU}>\mathrm{PY}=\mathrm{DBT}$ in $\mathrm{CH}_{3} \mathrm{CN}$, in better agreement with the theoretical orders for solvated rather than unsolvated analyte ions. Protonated molecules of FLU and CAR should solvate more readily and thus become ionized more efficiently than PY or DBT.

For charge exchange, the exothermicity order from theory (in a given solvent) is CAR $>$ PY $>$ DBT $>$ FLU with analyte solvation and $\mathrm{PY}>\mathrm{CAR}>\mathrm{DBT}>\mathrm{FLU}$ without solvation. Again, the experimentally observed order agrees better with the theoretical when analyte solvation is assumed to occur than when it is not. The experimental charge exchange order in $\mathrm{CH}_{3} \mathrm{CN}$ is $\mathrm{CAR}>$ PY $>$ DBT $>$ FLU, the same as predicted by calculations considering solvation. However, for $\mathrm{CH}_{3} \mathrm{OH}$ the agreement with the experimental order, $\mathrm{CAR}>$ FLU $>$ DBT $>$ PY, is not as good. On the whole, the calculated thermodynamic data indicate that solvated analyte and solvent ions are probably the species involved in the proton transfer and charge exchange reactions occurring in the APCI ion source.

In considering whether proton transfer occurs more readily from the protonated solvent molecule, Reaction 
Table 9. Theoretical and experimental (in parentheses from Table 6) thermodynamic data for the charge exchange reaction (16) with $\mathrm{CH}_{3} \mathrm{OH}$ and $\mathrm{CH}_{3} \mathrm{CN}$ as solvent $\left(\Delta \mathrm{H}^{\circ}\right.$ and $\Delta \mathrm{G}^{\circ}$ in $\left.\mathrm{eV}\right)$

\begin{tabular}{|c|c|c|c|c|}
\hline \multirow[b]{2}{*}{ Reaction } & \multicolumn{2}{|c|}{$\Delta \mathrm{H}^{\circ}$} & \multicolumn{2}{|c|}{$\Delta \mathrm{G}^{\circ}$} \\
\hline & $\mathrm{CH}_{3} \mathrm{OH}$ & $\mathrm{CH}_{3} \mathrm{CN}$ & $\mathrm{CH}_{3} \mathrm{OH}$ & $\mathrm{CH}_{3} \mathrm{CN}$ \\
\hline \multicolumn{5}{|l|}{$\mathrm{A}+\mathrm{S}^{+\cdot} \rightarrow \mathrm{A}^{+\cdot}+\mathrm{S}$} \\
\hline PY & $-3.47(-3.44)$ & $-4.83(-4.79)$ & -3.47 & -4.79 \\
\hline CAR & $-3.23(-3.35)$ & $-4.59(-4.70)$ & -3.22 & -4.54 \\
\hline DBT & $-2.86(-2.84)$ & $-4.22(-4.19)$ & -2.87 & -4.18 \\
\hline FLU & $-2.52(-2.56)$ & $-3.88(-3.91)$ & -2.53 & -3.84 \\
\hline \multicolumn{5}{|c|}{$A+(S) S^{+\cdot} \rightarrow A^{+\cdot}+2 S$} \\
\hline PY & -1.70 & -2.11 & -2.08 & -2.55 \\
\hline CAR & -1.45 & -1.87 & -1.83 & -2.30 \\
\hline DBT & -1.08 & -1.50 & -1.47 & -1.94 \\
\hline FLU & -0.74 & -1.15 & -1.14 & -1.60 \\
\hline \multicolumn{5}{|c|}{$\mathrm{A}+(\mathrm{S})_{2} \mathrm{~S}^{+\cdot} \rightarrow \mathrm{A}^{+\cdot}+3 \mathrm{~S}$} \\
\hline PY & -0.59 & -1.49 & -1.34 & -2.37 \\
\hline CAR & -0.35 & -1.25 & -1.09 & -2.12 \\
\hline DBT & +0.03 & -0.88 & -0.73 & -1.76 \\
\hline FLU & +0.37 & -0.53 & -0.40 & -1.42 \\
\hline \multicolumn{5}{|l|}{$\mathrm{A}+\mathrm{S}^{+\cdot} \rightarrow(\mathrm{S}) \mathrm{A}^{+\cdot}$} \\
\hline CAR & -3.92 & -5.35 & -3.54 & -5.01 \\
\hline PY & -3.83 & -5.18 & -3.51 & -4.89 \\
\hline DBT & -3.26 & -4.65 & -2.92 & -4.36 \\
\hline FLU & -2.96 & -4.36 & -2.61 & -4.06 \\
\hline \multicolumn{5}{|c|}{$A+(S) S^{+\cdot} \rightarrow(S) A^{+\cdot}+S$} \\
\hline CAR & -2.15 & -2.62 & -2.15 & -2.77 \\
\hline PY & -2.05 & -2.45 & -2.12 & -2.65 \\
\hline DBT & -1.48 & -1.93 & -1.52 & -2.11 \\
\hline FLU & -1.18 & -1.63 & -1.22 & -1.82 \\
\hline \multicolumn{5}{|c|}{$\mathrm{A}+(\mathrm{S})_{2} \mathrm{~S}^{+\cdot} \rightarrow(\mathrm{S}) \mathrm{A}^{+\cdot}+2 \mathrm{~S}$} \\
\hline CAR & -1.04 & -2.00 & -1.41 & -2.59 \\
\hline PY & -0.94 & -1.83 & -1.38 & -2.48 \\
\hline DBT & -0.37 & -1.31 & -0.78 & -1.94 \\
\hline FLU & -0.07 & -1.01 & -0.48 & -1.64 \\
\hline
\end{tabular}

(17), or from the solvent radical cation, Reaction (18), the theoretical calculations suggest that in the vast majority of cases, transfer from the radical cation is more exothermic and more spontaneous. The exothermicity order of the analytes for both reactions is the same and for the cases of solvated analyte ions it is in agreement with the experimental ionization order for $\mathrm{CH}_{3} \mathrm{OH}$, but not for $\mathrm{CH}_{3} \mathrm{CN}$. However, it should be noted that the reactants for Reaction (16), charge exchange, and Reaction (18), proton transfer, are the same (for the same extent of solvation). Thus, there will be a direct competition between charge exchange and proton transfer when an analyte molecule collides with a solvent radical cation. On an energetic basis, charge exchange is preferred by about 1 to $1.5 \mathrm{eV}$ for all model compounds except FLU, which is favored by only about 0.7 to $0.1 \mathrm{eV}$, with solvation effects leading to a higher preference for proton transfer. Assuming that these energetically-favored, ion-molecule reactions are rapid, as indicated by Harrison [36], this suggests that all model compounds, with the possible exception of FLU, will undergo charge exchange, not proton transfer, on collision with a solvent radical cation. Thus formation of $\mathrm{AH}^{+}$is more likely to occur via proton transfer from the protonated solvent ion, Reaction (17), and the amount of charge exchange compared with proton transfer ionization will depend both on reaction energetics and the concentrations of the various reagent ions present in the plasma. Experimentally, both proton transfer and charge exchange occur more readily in $\mathrm{CH}_{3} \mathrm{CN}$ than in $\mathrm{CH}_{3} \mathrm{OH}$. This is in agreement with the data in Tables 9 and 11 and some of the cases in Table 10 also.

An interesting observation was made when testing commercial PY. As mentioned in the Experimental section, commercial PY (both 95\% and Gold Label) contained an impurity $(m / z$ 203) that reacted with $\mathrm{HCl}_{(\mathrm{aq})}$ and that produced an abundant $\mathrm{MH}^{+}$ion $(\mathrm{m} / \mathrm{z}$ 204) in $\mathrm{CH}_{3} \mathrm{OH}$. The $\mathrm{M}^{+\cdot}$ peak from electron ionization of the impurity has an accurate mass of $203.0740 \pm$ $0.0008 \mathrm{u}$, indicating uniquely a nitrogen-containing compound with chemical composition $\mathrm{C}_{15} \mathrm{H}_{9} \mathrm{~N}$ (calculated mass $203.0735 \mathrm{u}$ ), most probably one of three possible azapyrene isomers. In $\mathrm{CH}_{3} \mathrm{OH}$ the ion counts for the $\mathrm{MH}^{+}$ion of the impurity in a sample of impure PY were about 30 times higher than the total ion counts for the PY in the same sample $\left([\mathrm{PY}]=1.0 \times 10^{-5} \mathrm{~mol}\right.$ $\left.\mathrm{L}^{-1}\right)$, and higher than the TICs for all PACs, except FLU $\left([\mathrm{PAC}]=1.0 \times 10^{-5} \mathrm{~mol} \mathrm{~L}^{-1}\right)$. In $\mathrm{CH}_{3} \mathrm{CN}$ and $\mathrm{C}_{7} \mathrm{H}_{8}$ the ion counts for the impurity were less than $5 \%$ of those for the PY, lower than the total ion counts for any of the PACs studied here $\left([\mathrm{PAC}]=1.0 \times 10^{-5} \mathrm{~mol} \mathrm{~L}^{-1}\right)$. 
Table 10. Theoretical and experimental (in parentheses from Table 7) thermodynamic data for the proton transfer reaction (17) with $\mathrm{CH}_{3} \mathrm{OH}$ and $\mathrm{CH}_{3} \mathrm{CN}$ as solvent $\left(\Delta \mathrm{H}^{\circ}\right.$ and $\Delta \mathrm{G}^{\circ}$ in $\left.\mathrm{eV}\right)$

\begin{tabular}{|c|c|c|c|c|}
\hline \multirow[b]{2}{*}{ Reaction } & \multicolumn{2}{|c|}{$\Delta \mathrm{H}^{\circ}$} & \multicolumn{2}{|c|}{$\Delta \mathrm{G}^{\circ}$} \\
\hline & $\mathrm{CH}_{3} \mathrm{OH}$ & $\mathrm{CH}_{3} \mathrm{CN}$ & $\mathrm{CH}_{3} \mathrm{OH}$ & $\mathrm{CH}_{3} \mathrm{CN}$ \\
\hline \multicolumn{5}{|l|}{$\mathrm{A}+\mathrm{SH}^{+} \rightarrow \mathrm{AH}^{+}+\mathrm{S}$} \\
\hline PY & $-1.52(-1.32)$ & $-1.24(-1.06)$ & -1.57 & -1.29 \\
\hline CAR & $-1.43(-1.23)$ & $-1.15(-0.97)$ & -1.44 & -1.17 \\
\hline FLU & $-1.32(-1.16)$ & $-1.04(-0.90)$ & -1.33 & -1.05 \\
\hline DBT & $-0.92(-0.74)$ & $-0.65(-0.48)$ & -0.95 & -0.68 \\
\hline \multicolumn{5}{|c|}{$\mathrm{A}+(\mathrm{S}) \mathrm{SH}^{+} \rightarrow \mathrm{AH}^{+}+2 \mathrm{~S}$} \\
\hline PY & +0.08 & +0.21 & -0.39 & -0.16 \\
\hline CAR & +0.17 & +0.30 & -0.27 & -0.04 \\
\hline FLU & +0.28 & +0.41 & -0.15 & +0.08 \\
\hline DBT & +0.68 & +0.80 & +0.22 & +0.45 \\
\hline \multicolumn{5}{|c|}{$\mathrm{A}+(\mathrm{S})_{2} \mathrm{SH}^{+} \rightarrow \mathrm{AH}^{+}+3 \mathrm{~S}$} \\
\hline PY & +1.05 & +0.54 & +0.23 & -0.01 \\
\hline CAR & +1.14 & +0.63 & +0.36 & +0.11 \\
\hline FLU & +1.25 & +0.74 & +0.47 & +0.22 \\
\hline DBT & +1.64 & +1.14 & +0.85 & +0.60 \\
\hline \multicolumn{5}{|l|}{$\mathrm{A}+\mathrm{SH}^{+} \rightarrow(\mathrm{S}) \mathrm{AH}^{+}$} \\
\hline FLU & -2.29 & -2.01 & -1.88 & -1.70 \\
\hline CAR & -2.09 & -1.78 & -1.71 & -1.51 \\
\hline PY & -1.84 & -1.61 & -1.54 & -1.42 \\
\hline DBT & -1.30 & -1.09 & -0.99 & -0.86 \\
\hline \multicolumn{5}{|c|}{$\mathrm{A}+(\mathrm{S}) \mathrm{SH}^{+} \rightarrow(\mathrm{S}) \mathrm{AH}^{+}+\mathrm{S}$} \\
\hline FLU & -0.69 & -0.56 & -0.70 & -0.57 \\
\hline CAR & -0.48 & -0.33 & -0.53 & -0.38 \\
\hline PY & -0.24 & -0.16 & -0.37 & -0.29 \\
\hline DBT & +0.30 & +0.36 & +0.18 & +0.27 \\
\hline \multicolumn{5}{|c|}{$\mathrm{A}+(\mathrm{S})_{2} \mathrm{SH}^{+} \rightarrow(\mathrm{S}) \mathrm{AH}^{+}+2 \mathrm{~S}$} \\
\hline FLU & +0.28 & -0.22 & -0.08 & -0.42 \\
\hline CAR & +0.48 & +0.00 & +0.20 & -0.23 \\
\hline PY & +0.73 & +0.17 & +0.25 & -0.14 \\
\hline DBT & +1.27 & +0.69 & +0.80 & +0.42 \\
\hline
\end{tabular}

The ionization efficiency of the impurity was similar in the three solvents tested, unlike the model compounds. The much higher ionization efficiency of the impurity in $\mathrm{CH}_{3} \mathrm{OH}$ relative to other PACs suggests that, on an absolute basis, $\mathrm{CH}_{3} \mathrm{OH}$ provided the best medium for proton transfer, and that the ionization of nitrogen-containing bases that protonate on the heteroatom was not affected by solvation of the solvent to a large extent whereas compounds that protonate on carbon (CAR, DBT, and PY) will be much more affected, regardless of their relatively high gas-phase basicities (calculations indicate that the favored site of protonation for DBT and CAR is a carbon atom, not the heteroatom, whereas for FLU, the preferred site is oxygen).

Kebarle and associates [34, 37] also observed, under conditions where protonated water clusters are thought to be the reagent ions, much higher sensitivities for nitrogen-containing bases such as amines and pyridines, that have high gas-phase basicities $(>8.7 \mathrm{eV})$ and that can form relatively stable clusters between the solvent and the protonated analyte. Compounds that protonate on oxygen, e.g., methanol and acetone, can also form relatively stable clusters but their gas-phase basicities are lower $(<8.7 \mathrm{eV})$, resulting in lower sensitivities. On the other hand, the protonated molecules of compounds that protonate on sulfur or carbon, such as dimethyl sulfide, thiophene, pyrrole, and PAHs, form clusters of very low stability because of the poor ability of their conjugated acids to form hydrogen bonds. Consequently, the sensitivities observed for these analytes were much lower.

The results shown above for $\mathrm{CH}_{3} \mathrm{OH}$ indicate that a similar situation occurs in this case. For bases which have high gas-phase basicities and which form stable clusters, ionization by proton transfer will occur as readily in $\mathrm{CH}_{3} \mathrm{OH}$ as in $\mathrm{CH}_{3} \mathrm{CN}$, but not for bases of lower gas-phase basicity or for compounds that do not form stable clusters. In the case of the azapyrene impurity, the simple proton transfer reaction is quite exothermic (the gas-phase basicity of a similar base, quinoline, is $9.5 \mathrm{eV}$ ). Although the gas-phase basicity of CAR is expected to be similar to that of azapyrene (indole and pyridine have similar gas-phase basicities $\sim 9.3 \mathrm{eV}$ ), the ionization efficiency of CAR is lower than that of azapyrene. Protonated azapyrene would be able to form more stable clusters than protonated CAR, providing higher sensitivity.

Short et al. [17] have observed in APPI that the sensitivities for some model PAHs are higher when the solvent is $\mathrm{CH}_{3} \mathrm{OH}$ rather than $\mathrm{CH}_{3} \mathrm{CN}$, the opposite of what we have observed for APCI. The primary source 
Table 11. Theoretical and experimental (in parentheses from Table 7) thermodynamic data for the proton transfer reaction (18) with $\mathrm{CH}_{3} \mathrm{OH}$ and $\mathrm{CH}_{3} \mathrm{CN}$ as solvent $\left(\Delta \mathrm{H}^{\circ}\right.$ and $\Delta \mathrm{G}^{\circ}$ in $\left.\mathrm{eV}\right)$

\begin{tabular}{|c|c|c|c|c|}
\hline \multirow[b]{2}{*}{ Reaction } & \multicolumn{2}{|c|}{$\Delta \mathrm{H}^{\circ}$} & \multicolumn{2}{|c|}{$\Delta \mathrm{G}^{\circ}$} \\
\hline & $\mathrm{CH}_{3} \mathrm{OH}$ & $\mathrm{CH}_{3} \mathrm{CN}$ & $\mathrm{CH}_{3} \mathrm{OH}$ & $\mathrm{CH}_{3} \mathrm{CN}$ \\
\hline \multicolumn{5}{|c|}{$\mathrm{A}+\mathrm{S}^{+\cdot} \rightarrow \mathrm{AH}^{+}+[\mathrm{S}-\mathrm{H}]^{\cdot}$} \\
\hline PY & $-2.05(-2.19)$ & $-3.48(-3.65)$ & -2.10 & -3.49 \\
\hline CAR & $-1.96(-2.10)$ & $-3.39(-3.56)$ & -1.97 & -3.36 \\
\hline FLU & $-1.85(-2.03)$ & $-3.28(-3.49)$ & -1.86 & -3.25 \\
\hline DBT & $-1.45(-1.61)$ & $-2.88(-3.07)$ & -1.47 & -2.87 \\
\hline \multicolumn{5}{|c|}{$\mathrm{A}+(\mathrm{S}) \mathrm{S}^{+\cdot} \rightarrow \mathrm{AH}^{+}+\mathrm{S}[\mathrm{S}-\mathrm{H}]^{-}$} \\
\hline PY & -0.59 & -0.91 & -0.68 & -1.11 \\
\hline CAR & -0.50 & -0.82 & -0.55 & -0.98 \\
\hline FLU & -0.30 & -0.70 & -0.44 & -0.87 \\
\hline DBT & 0.00 & -0.31 & -0.05 & -0.49 \\
\hline \multicolumn{5}{|c|}{$\mathrm{A}+(\mathrm{S})_{2} \mathrm{~S}^{+\cdot} \rightarrow \mathrm{AH}^{+}+\mathrm{S}[\mathrm{S}-\mathrm{H}]^{\cdot}+\mathrm{S}$} \\
\hline PY & +0.52 & -0.29 & +0.06 & -0.94 \\
\hline CAR & +0.61 & -0.19 & +0.19 & -0.81 \\
\hline FLU & +0.72 & -0.08 & +0.30 & -0.70 \\
\hline DBT & +1.11 & +0.31 & +0.69 & -0.31 \\
\hline \multicolumn{5}{|c|}{$\mathrm{A}+(\mathrm{S}) \mathrm{S}^{+\cdot} \rightarrow(\mathrm{S}) \mathrm{AH}^{+}+[\mathrm{S}-\mathrm{H}]^{\cdot}$} \\
\hline FLU & -1.05 & -1.52 & -1.02 & -1.66 \\
\hline CAR & -0.84 & -1.30 & -0.85 & -1.47 \\
\hline PY & -0.60 & -1.13 & -0.69 & -1.38 \\
\hline DBT & -0.05 & -0.61 & -0.13 & -0.81 \\
\hline \multicolumn{5}{|c|}{$\mathrm{A}+(\mathrm{S})_{2} \mathrm{~S}^{+\cdot} \rightarrow(\mathrm{S}) \mathrm{AH}^{+}+\mathrm{S}[\mathrm{S}-\mathrm{H}]^{-}$} \\
\hline FLU & -0.26 & -1.05 & -0.25 & -1.34 \\
\hline CAR & -0.05 & -0.83 & -0.08 & -1.15 \\
\hline PY & +0.19 & -0.66 & +0.08 & -1.06 \\
\hline DBT & +0.74 & -0.14 & +0.64 & -0.50 \\
\hline
\end{tabular}

of ions in APPI is ultraviolet photons, while in APCI it is a corona discharge. Nevertheless, there are certain similarities between the ionization pathways. They explain their results by noting that their radiation has enough energy to ionize $\mathrm{CH}_{3} \mathrm{OH}$, but not $\mathrm{CH}_{3} \mathrm{CN}$; however, $\mathrm{CH}_{3} \mathrm{CN}$ can still absorb a large portion of the ionizing radiation, lowering sensitivity. In the case of $\mathrm{CH}_{3} \mathrm{OH}$, the ionized solvent can then ionize the analyte in much the same way as happens in APCI and they observe a mixture of charge exchange and proton transfer as reported here.

Syage [16] and Short et al. [17] have proposed that hydrogen atom abstraction from solvent molecules by analyte radical cations is the source of protonated analyte molecules often observed in APPI.

$$
\mathrm{A}^{+\cdot}+\mathrm{S}_{\mathrm{n}} \rightarrow(\mathrm{S})_{\mathrm{n}-\mathrm{h}-\mathrm{i}-1} \mathrm{AH}^{+}+\mathrm{S}_{\mathrm{i}}[\mathrm{S}-\mathrm{H}]+\mathrm{hS}
$$

To determine whether this might be a possible source of protonated analyte molecules in APCI, we have calculated thermodynamic data for Reaction (23), which are presented in Table 12.

The data in this table indicate that the hydrogen atom abstraction reaction is endothermic and nonspontaneous (under standard conditions) for all analytes under almost all conditions. The favorability order, FLU > $\mathrm{CAR}>\mathrm{DBT} \approx \mathrm{PY}$, is the same regardless of solvation of the analyte ion and is in reasonable agreement with the observed relative ionization efficiencies, FLU $>$ CAR $>$ $\mathrm{PY}>\mathrm{DBT}$ for $\mathrm{CH}_{3} \mathrm{OH}$ and $\mathrm{CAR}>\mathrm{FLU}>\mathrm{PY} \approx \mathrm{DBT}$ for
$\mathrm{CH}_{3} \mathrm{CN}$. However, the theoretical calculations indicate very little difference between the $\Delta \mathrm{H}^{\circ}$ and $\Delta \mathrm{G}^{\circ}$ values in $\mathrm{CH}_{3} \mathrm{OH}$ and $\mathrm{CH}_{3} \mathrm{CN}$, which does not explain the much greater ionization efficiency in $\mathrm{CH}_{3} \mathrm{CN}$. If hydrogen atom abstraction by analyte radical cations were a major source of protonated analyte molecules in APCI, one would not expect to observe analyte radical cations to any extent in the mass spectrum, which in practice are observed for many compounds. Thus hydrogen atom abstraction is an unlikely source of protonated analyte ions in APCI.

\section{Conclusions}

Conclusions regarding ionization mechanisms and solvation effects have been presented above. With regard to analytical considerations, our results indicate that $\mathrm{CH}_{3} \mathrm{CN}$ is superior to $\mathrm{CH}_{3} \mathrm{OH}$ as a solvent (with regard to APCI response, but not necessarily with regard to chromatographic behavior), providing better LODs and less interference between PACs in the linear response region. The exception to this involves nitrogen-containing bases of high gas-phase basicity, which ionize as efficiently in $\mathrm{CH}_{3} \mathrm{OH}$ as in $\mathrm{CH}_{3} \mathrm{CN}$ by proton transfer. For the best LODs in $\mathrm{CH}_{3} \mathrm{CN}$, high solvent flow rates should be used but, if high sensitivity is not a requirement, a low solvent flow rate would provide savings in solvent, a wider linear range, and less deviation from linearity at higher concentrations. Sensitivity is less affected by solvent flow rate in $\mathrm{CH}_{3} \mathrm{OH}$ with better results obtained at 
Table 12. Theoretical thermodynamic data for the hydrogen atom abstraction reaction (23) with $\mathrm{CH}_{3} \mathrm{OH}$ and $\mathrm{CH}_{3} \mathrm{CN}_{\text {as }}$ solvent $\left(\Delta \mathrm{H}^{\circ}\right.$ and $\Delta \mathrm{G}^{\circ}$ in $\left.\mathrm{eV}\right)$

\begin{tabular}{|c|c|c|c|c|}
\hline \multirow[b]{2}{*}{ Reaction } & \multicolumn{2}{|c|}{$\Delta \mathrm{H}^{\circ}$} & \multicolumn{2}{|c|}{$\Delta \mathrm{G}^{\circ}$} \\
\hline & $\mathrm{CH}_{3} \mathrm{OH}$ & $\mathrm{CH}_{3} \mathrm{CN}$ & $\mathrm{CH}_{3} \mathrm{OH}$ & $\mathrm{CH}_{3} \mathrm{CN}$ \\
\hline \multicolumn{5}{|c|}{$\overline{\mathrm{A}^{+\cdot}+\mathrm{S} \rightarrow \mathrm{AH}^{+}+[\mathrm{S}-\mathrm{H}]}$} \\
\hline FLU & +0.67 & +0.60 & +0.67 & +0.59 \\
\hline CAR & +1.27 & +1.20 & +1.25 & +1.17 \\
\hline DBT & +1.41 & +1.34 & +1.38 & +1.30 \\
\hline PY & +1.42 & +1.35 & +1.38 & +1.29 \\
\hline \multicolumn{5}{|c|}{$\mathrm{A}^{+\cdot}+\mathrm{S}_{2} \rightarrow \mathrm{AH}^{+}+\mathrm{S}[\mathrm{S}-\mathrm{H}]^{\cdot}$} \\
\hline FLU & +0.60 & +0.62 & +0.60 & +0.59 \\
\hline CAR & +1.20 & +1.22 & +1.19 & +1.18 \\
\hline DBT & +1.34 & +1.35 & +1.32 & +1.31 \\
\hline PY & +1.35 & +1.37 & +1.31 & +1.30 \\
\hline \multicolumn{5}{|c|}{$\mathrm{A}^{+\cdot}+\mathrm{S}_{3} \rightarrow \mathrm{AH}^{+}+\mathrm{S}[\mathrm{S}-\mathrm{H}]^{-}+\mathrm{S}$} \\
\hline FLU & +1.23 & +0.82 & +0.76 & +0.53 \\
\hline CAR & +1.83 & +1.43 & +1.35 & +1.11 \\
\hline DBT & +1.97 & +1.56 & +1.48 & +1.24 \\
\hline PY & +1.98 & +1.58 & +1.47 & +1.23 \\
\hline \multicolumn{5}{|c|}{$\mathrm{A}^{+\cdot}+\mathrm{S}_{2} \rightarrow(\mathrm{S}) \mathrm{AH}^{+}+[\mathrm{S}-\mathrm{H}]^{-}$} \\
\hline FLU & -0.06 & -0.20 & +0.02 & -0.20 \\
\hline CAR & +0.86 & +0.74 & +0.89 & +0.69 \\
\hline DBT & +1.28 & +1.06 & +1.24 & +0.98 \\
\hline PY & +1.35 & +1.15 & +1.30 & +1.03 \\
\hline \multicolumn{5}{|c|}{$\mathrm{A}^{+\cdot}+\mathrm{S}_{3} \rightarrow(\mathrm{S}) \mathrm{AH}^{+}+\mathrm{S}[\mathrm{S}-\mathrm{H}]^{\cdot}$} \\
\hline FLU & +0.25 & -0.14 & +0.21 & -0.12 \\
\hline CAR & +1.17 & +0.80 & +1.08 & +0.77 \\
\hline DBT & +1.59 & +1.11 & +1.43 & +1.06 \\
\hline PY & +1.66 & +1.21 & +1.49 & +1.11 \\
\hline
\end{tabular}

low flow rates in many cases. For complex samples where chromatography does not resolve compounds, care should be taken to operate in the linear response region, especially for quantitative purposes. The ability to ionize by charge exchange as well as by proton transfer should be kept in mind, both for identification and sensitivity purposes.

\section{Acknowledgments}

L.C.H. thanks Dalhousie University and MDS SCIEX for scholarship support; other funding was provided by the Trace Analysis Research Centre at Dalhousie University. Additional thanks are due to Xiao Feng of the Dalhousie University Mass Spectrometry Laboratory.

\section{References}

1. Marr, L. C.; Kirchstetter, T. W.; Harley, R. A.; Miguel, A. H.; Hering, S. V.; Hammond, S. K. Characterization of Polycyclic Aromatic Hydrocarbons in Motor Vehicle Fuels and Exhaust Emissions. Environ. Sci. Technol. 1999, 33, 3091-3099.

2. Dimashki, M.; Harrad, S.; Harrison, R. M. Measurements of Nitro-PAH in the Atmospheres of Two Cities. Atmos. Environ. 2000, 34, 2459-2469.

3. Kropp, K. G.; Fedorak, P. M. A Review of the Occurrence, Toxicity, and Biodegradation of Condensed Thiophenes Found in Petroleum. Can. J. Microbiol. 1998, 44, 605-622.

4. Mendez, A.; Bruzual, J. Molecular Characterization of Petroleum and Its Fractions by Mass Spectrometry. In Analytical Advances for Hydrocarbon Research, Chap. 4, Hsu, C. S., Ed.; Kluwer Academic/Plenum Publishers: New York, NY, 2003, pp 81-87.

5. Vo-Dinh, T. In Chemical Analysis of Polycyclic Aromatic Compounds, Chap. 3. John Wiley, Inc.: New York, NY, 1989, pp 59-73.

6. Thomson, B. A. Atmospheric Pressure Ionization and Liquid Chromatography/Mass Spectrometry-Together at Last. J. Am. Soc. Mass Spectrom. 1998, 9, 187-193.
7. Roussis, S. G.; Proulx, R. Molecular Weight Distributions of Heavy Aromatic Petroleum Fractions by $\mathrm{Ag}^{+}$Electrospray Ionization Mass Spectrometry. Anal. Chem. 2002, 74, 1408-1414.

8. Kolakowski, B. M.; Grossert, J. S.; Ramaley, L. The Importance of Both Charge Exchange and Proton Transfer in the Analysis of Polycyclic Aromatic Compounds using Atmospheric Pressure Chemical Ionization Mass Spectrometry. J. Am. Soc. Mass Spectrom. 2004, 15, 301-310.

9. Hanold, K. A.; Fischer, S. M.; Cormia, P. H.; Miller, C. E.; Syage, J. A Atmospheric Pressure Photoionization. 1. General Properties for LC/ MS. Anal. Chem. 2004, 76, 2842-2851.

10. Anacleto, J. F.; Ramaley, L.; Benoit, F. M.; Boyd, R. K.; Quilliam, M. A. Comparison of Liquid Chromatography/Mass Spectrometry Interfaces for the Analysis of Polycyclic Aromatic Hydrocarbons. Anal. Chem. 1995, 67, 4145-4154.

11. Hayen, H.; Jachmann, N.; Vogel, M.; Karst, U. LC Electron Capture APCI-MS for the Determination of Nitroaromatic Compounds. Analyst 2002, 127, 1027-1030.

12. Roussis, S. G.; Fedora, J. W. Quantitative Determination of Polar and Ionic Compounds in Petroleum Fractions by Atmospheric Pressure Chemical Ionization and Electrospray Ionization Mass Spectrometry. Rapid Commun. Mass Spectrom. 2002, 16, 1295-1303.

13. Cody, R. B.; Laramée, J. A.; Durst, H. D. Versatile New Ion Source for the Analysis of Materials in Open Air under Ambient Conditions. Anal. Chem. 2005, 77, 2297-2303.

14. McEwen, C. N.; McKay, R. G.; Larsen, B. S. Analysis of Solids, Liquids, and Biological Tissues Using Solids Probe Introduction at Atmospheric Pressure on Commercial LC/MS Instruments. Anal. Chem. 2005, 77, 7826-7831.

15. Ratcliffe, L. V.; Rutten, F. J. M.; Barrett, D. A.; Whitmore, T.; Seymour, D.; Greenwood, C.; Aranda-Gonzalvo, Y.; Robinson, S.; McCoustra, M. Surface Analysis under Ambient Conditions Using Plasma-Assisted Desorption/Ionization Mass Spectrometry. Anal. Chem. 2007, 79, 60946101.

16. Syage, J. A. Mechanism of $[\mathrm{M}+\mathrm{H}]^{+}$Formation in Photoionization Mass Spectrometry. J. Am. Soc. Mass Spectrom. 2004, 15, 1521-1533.

17. Short, L.C.; Cai, S.-S.; Syage, J. A. APPI-MS: Effects of Mobile Phases and VUV Lamps on the Detection of PAH Compounds. J. Am. Soc. Mass Spectrom. 2007, 18, 589-599.

18. Kolakowski, B. M.; Grossert, J. S.; Ramaley, L. Studies on the PositiveIon Mass Spectra from Atmospheric Pressure Chemical Ionization of Gases and Solvents used in Liquid Chromatography and Direct Liquid Injection. J. Am. Soc. Mass Spectrom. 2004, 15, 311-324.

19. Frisch, M. J.; Trucks, G. W.; Schlegel, H. B.; Scuseria, G. E.; Robb, M. A. Cheeseman, J. R.; Montgomery, Jr., J. A.; Vreven, T.; Kudin, K. N.; 
Burant, J. C.; Millam, J. M.; Iyengar, S. S.; Tomasi, J.; Barone, V.; Mennucci, B.; Cossi, M.; Scalmani, G.; Rega, N.; Petersson, G. A.; Nakatsuji, H.; Hada, M.; Ehara, M.; Toyota, K.; Fukuda, R.; Hasegawa, J.; Ishida, M.; Nakajima, T.; Honda, Y.; Kitao, O.; Nakai, H.; Klene, M.; Li, X.; Knox, J. E.; Hratchian, H. P.; Cross, J. B.; Adamo, C.; Jaramillo, J.; Gomperts, R.; Stratmann, R. E.; Yazyev, O.; Austin, A. J.; Cammi, R.; Pomelli, C.: Ochterski, J. W.; Ayala, P. Y.; Morokuma, K.; Voth, G. A. Salvador, P.; Dannenberg, J. J.; Zakrzewski, V. G.; Dapprich, S.; Daniels, A. D.; Strain, M. C.; Farkas, O.; Malick, D. K.; Rabuck, A. D.; Raghavachari, K.; Foresman, J. B.; Ortiz, J. V.; Cui, Q.; Baboul, A. G.; Clifford, S.; Cioslowski, J.; Stefanov, B. B.; Liu, G.; Liashenko, A. Piskorz, P.; Komaromi, I.; Martin, R. L.; Fox, D. J.; Keith, T.; Al-Laham, M. A.; Peng, C. Y.; Nanayakkara, A.; Challacombe, M.; Gill, P. M. W.; Johnson, B.; Chen, W.; Wong, M. W.; Gonzalez, C.; Pople, J. A. Gaussian-03, Gaussian Inc., Pittsburgh PA, 2003.

20. Becke, A. D. A New Mixing of Hartree-Fock and Local DensityFunctional Theory. J. Chem. Phys. 1993, 98, 1372-1377.

21. Lee, C.; Yang, W.; Parr, R. G. Development of the Colle-Salvetti Correlation-Energy Formula into a Functional of the Electron Density. Phys. Rev. 1988, B37, 785-789.

22. Malavé Osuna, R.; Ponce Ortiz, R.; Okamoto, T.; Suzuki, Y.; Yamaguchi, S.; Hernández, V.; López Navarrete, J. T. Thiophene- and SelenopheneBased Heteroacenes: Combined Quantum Chemical DFT and Spectroscopic Raman and UV-Vis-NIR Study. J. Phys. Chem. B 2007, 111, 7488-7496.

23. Hwang, S.; Chung, D. S. Calculation of the Solvation Free Energy of the Proton in Methanol. Bull Korean Chem. Soc. 2005, 26, 589-593.

24. Suzuki, A.; Kinoshita, T.; Takeuchi, K.; Wakisaka, A.; Yoshizawa, K. Theoretical Study on the Structure and Stability of the Clusters of Tropylium Ion Solvated by Methanol Molecules. J. Mol. Struct. (Theochem). 2001, 574, 117-125.

25. Mata, R. A.; Costa Cabral, B. J. Structural, Energetic, and Electronic Properties of $\left(\mathrm{CH}_{3} \mathrm{CN}\right)_{2-8}$ Clusters by Density Functional Theory. J. Mol. Struct. (Theochem). 2004, 673, 155-164.

26. Perdew, J. P; Burke, K.; Ernzerhof, M. Generalized Gradient Approximation Made Simple. Phys. Rev. Lett. 1996, 77, 3865-3868.

27. Scott, A. P. Radom, L. Harmonic Vibrational Frequencies: An Evaluation of Hartree-Fock, Møller-Plesset, Quadratic Configuration Interaction, Density Functional Theory, and Semiempirical Scale Factors. J. Phys. Chem. 1996, 100, 16502-16513.

28. Lias, S. G. Ionization Energy Evaluation and Lias, S. G.; Levin, R. D. Kafafi, S. A.; Rosenstock, H. M.; Draxl, K.; Steiner, B. W.; Herron, J. T.,
Ion Energetics Data. Number 69, Linstrom, P. J.; Mallard, W. G., Eds.; In NIST Chemistry WebBook, NIST Standard Reference Database National Institute of Standards and Technology: Gaithersburg MD, 2005; http://webbook.nist.gov.

29. Hunter, E. P. Lias, S, G. J. Proton Affinity Evaluation. Number 69 Linstrom, P. J.; Mallard, W. G., Eds.; In NIST Chemistry WebBook, NIST Standard Reference Database National Institute of Standards and Technology; Gaithersburg MD, 2005; http://webbook.nist.gov.

30. Harrison, A. G. Chemical Ionization Mass Spectrometry, 2nd ed.; CRC Press: Boca Raton, FL, 1992; Chap. 2, p 13.

31. Luo, Y. R. Handbook of Bond Dissociation Energies in Organic Compounds; CRC Press: Boca Raton, FL, 2003, pp 30, 31, 57, 76.

32. Horning, E. C.; Horning, M. G.; Carroll, D. I.; Stillwell, R. N. New Picogram Detection System Based on a Mass Spectrometer with an External Ionization Source at Atmospheric Pressure. Anal. Chem. 1973, 45, 936-943.

33. Dzidic, I; Carroll, D. I.; Stillwell, R. N.; Horning, E. C. Comparison of Positive Ions Formed in Nickel-63 and Corona Discharge Ion Sources Using Nitrogen, Argon, Isobutene, Ammonia, and Nitric Oxide as Reagents in Atmospheric Pressure Ionization Mass Spectrometry. Anal. Chem. 1976, 48, 1763-1768.

34. Sunner, J.; Nicol, G.; Kebarle, P. Factors Determining Relative Sensitivity of Analytes in Positive Mode Atmospheric Pressure Ionization Mass Spectrometry. Anal. Chem. 1988, 60, 1300-1307.

35. Carroll, D. I.; Dzidic, I.; Stillwell, R. N.; Haegele, K. D.; Horning, E. C. Atmospheric Pressure Ionization Mass Spectrometry: Corona Discharge Ion Source for Use in Liquid Chromatography-Mass SpectrometryComputer Analytical System. Anal. Chem. 1975, 47, 2369-2373.

36. Harrison, A. G. Chemical Ionization Mass Spectrometry, 2nd ed.; CRC Press: Boca Raton, FL, 1992; Chap. 2, pp 15-18.

37. Sunner, J.; Michael, G. I.; Kebarle, P. Sensitivity Enhancements Obtained at High Temperatures in Atmospheric Pressure Ionization Mass Spectrometry. Anal. Chem. 1988, 60, 1308-1313.

38. Meot-Ner (Mautner), M. Solvation of the Proton by $\mathrm{HCN}$ and $\mathrm{CH}_{3} \mathrm{CN}$ Condensation of HCN with Ions in the Gas Phase. J. Am. Chem. Soc 1978, 100, 4694-4699.

39. Kebarle, P.; Grimsrud, E. P. Gas Phase Ion Equilibria Studies of the Solvation of the Hydrogen Ion by Methanol, Dimethyl Ether, and Water. Effect of Hydrogen Bonding. J. Am. Chem. Soc. 1973, 95, 79397943. 